\title{
Development of Photoresponsive Coumarin-modified Ethylene-co- Vinyl Alcohol Copolymers with Antifouling Behavior
}

\author{
Cástor Salgado*, Marina P. Arrieta, Alberto Chiloeches, Alexandra Muñoz-Bonilla, \\ Laura Peponi, Daniel López, Marta Fernández-García* \\ Instituto de Ciencia y Tecnología de Polímeros (ICTP-CSIC), C/ Juan de la Cierva 3, \\ 28006 Madrid, Spain
}

Corresponding author: castorsalgado@ictp.csic.es (C.S.); martafg@ictp.csic.es (M.FG.)

\begin{abstract}
In this work, the modification of ethylene-co-vinyl alcohol (EVOH) copolymer with a coumarin derivative, 7-(hydroxyethoxy)-4-methyl coumarin (HEOMC), has been performed through the incorporation of different reactive groups, $p$-nitrophenyl chloroformate, succinic anhydride and phthalic anhydride as different linkers between coumarin and $\mathrm{EVOH}$ with the aim to obtain photo-responsive materials with improved protein absorption resistance. After purification, the modification degree was calculated by nuclear magnetic resonance and ultraviolet-visible spectroscopy. The thermal properties revealed the crystallinity loss and higher maximum degradation temperatures when EVOH is modified with coumarin derivative. Copolymers were successfully photo-crosslinked through the photo-responsive behavior of coumarin moieties. The micro-hardness test shown an increase of the mechanical performance due to the coumarin presence. The water contact angle measurements revealed that while coumarin-modified EVOH copolymers present a higher hydrophilic behavior than $\mathrm{EVOH}$, the photo-dimerization process mainly leads to slightly deviations on the surface wettability of neat EVOH. Finally, the absorption of bovine serum albumin onto the surface of the coumarin-modified materials revealed enhanced antifouling properties, particularly after the photo-crosslinked process. Therefore, the introduction of coumarin through different chain extenders leads to functional materials with tunable photo-responsive performance and protein absorption resistance.
\end{abstract}




\section{Keywords:}

Ethylene-co-vinyl alcohol copolymers; coumarin; modification; reactive groups; photoresponsive; coating; antifouling.

\section{Introduction}

The development of copolymers is an effective tool for modifying polymeric systems and therefore, to increase the number of applications in the industry. Ethyleneco-vinyl alcohol (EVOH) copolymer is a thermoplastic and semicrystalline copolymer synthesized from ethylene and vinyl acetate and posterior hydrolysis. EVOH presents good mechanical and optical properties, it keeps low permeability to $\mathrm{O}_{2}$ and $\mathrm{CO}_{2}$, and consequently it is a very suitable material for the development of inner layers in high barrier multilayer films for food packaging [1]. The hydroxyl groups of EVOH provide a high cohesive energy to the system, by leading to a decrease in the available free volume for exchange of gas and high oxygen barrier properties [2], also providing suitable hydroxyl sites to be easy used for further functionalization [3]. The ethylene molar content in $\mathrm{EVOH}$ is essential to determine characteristics like the melting point $\left(\mathrm{T}_{\mathrm{m}}\right)$ or the glass transition temperature $\left(\mathrm{T}_{\mathrm{g}}\right)$, which are also important for the processability of EVOH [4].

However, the presence of $-\mathrm{OH}$ groups triggers the absorption of water and provokes a decrease in the physical and mechanical properties. For this reason, an optimal method to reduce their affinity against water molecules is the partial modification of $-\mathrm{OH}$ groups. Thus, $\mathrm{EVOH}$ copolymers can be easily modified to obtain materials with tunable properties [5].

Coumarin is a natural compound habitually used in polymer chemistry due to their photo-responsive properties [6,7]. Coumarin derivatives are able to experiment reversible photo-dimerization and pho-cleavage processes under UV irradiation. At wavelengths close to $365 \mathrm{~nm}$, the double bond near to the lactone group undergoes a [ $2 \pi$ $+2 \pi$ ] cyclo-addition to form a cyclobutane ring [8]. The dimers can be photo-cleaved into monomers under irradiation of a UV light $(\lambda<260 \mathrm{~nm})$. These photochemical properties are used in the development of different photo-responsive polymeric systems $[9,10]$ like micelles [11], nanogels [12], nanocomposites [13] as well as shape memory polymers [14]. 
Besides, many coumarin derivatives have the capability to stabilize free radicals, generally leading to good anti-oxidant and anti-microbial activity [15]. These properties have also been used to enhance the thermal stability of several polymers [7, 16], or to provide antimicrobial behavior [17], respectively. Coumarin can also be effective as antifouling agent due to its lipophilic character and planar molecular structure $[18,19]$. In opposition to metallic biocides, coumarin is an environmental-friendly system to be incorporated in polymer coatings, affecting the biofilm formation and the progress of fouling sequence, as is the case when coumarin is incorporated into the matrix paints [20].

In this study, commercial EVOH copolymer with $56 \%$ of vinyl alcohol content is modified with coumarin to give enhanced and new properties such as photoresponsive behavior and antifouling properties. The EVOH is previously activated following three different strategies by incorporation of $p$-nitrophenyl chloroformate, succinic anhydride or phthalic anhydride. The substitution degree in each case is calculated by nuclear magnetic resonance $\left({ }^{1} \mathrm{H}-\mathrm{NMR}\right)$ and ultraviolet-visible (UV-vis) spectroscopy. The resulting materials with coumarin are characterized by Fourier Transform Infrared Spectroscopy (FTIR), ${ }^{1} \mathrm{H}$ and ${ }^{13} \mathrm{C}$ NMR. The photo-responsive properties are studied to evaluate the photo-dimerization and photo-cleavage of grafted coumarin moieties. In order to use these materials as potential polymer coatings, the thermal behavior, microhardness, surface wettability and antifouling properties are also analyzed.

\section{Experimental section}

\subsection{Materials}

EVOH copolymer with $56 \%$ of vinyl alcohol (density $=1.15 \mathrm{~g} \mathrm{~cm}^{-1}$, melt flow index $=\mathrm{g} 10 \mathrm{~min}^{-1}$ ) was supplied by Dupont, 1,4-dioxane, 2,2-dimethoxypropane, $N, N^{\prime}$ dicyclohexylcarbodiimide (DCC), dichloromethane (DCM), ethyl acetoacetate, resorcinol, 2-bromoethanol, ethyl acetate, 4-(dimethylamino)pyridine (DMAP), triethylamine (TEA), potassium carbonate, $N, N$-dimethylformamide (DMF), phosphorous pentoxide, p-nitrophenyl chloroformate, succinic anhydride, tetrahydrofuran (THF), phthalic anhydride, bovine serum albumin-fluorescein isothiocyanate conjugate (BSA-FITC) and Trizma® hydrochloride buffer solution (pH = 7.4) were supplied by Sigma-Aldrich. Acetone, DMF, $n$-hexane, chloroform, ethanol 
and methanol, were supplied by Scharlau. Sulfuric acid (98\%), dimethyl sulfoxide (DMSO) and pyridine were supplied by Panreac. N-methyl-2-pyrrolidone (NMP) and deuterated DMSO were supplied by Merck. TEA was distillated before used; the other products were used as received.

\subsection{Synthesis of coumarin derivative}

The synthesis of the coumarin derivative was carried out by following the procedure of Ling et al. [21] with some variations. Equimolar amounts of resorcinol $(35.6 \mathrm{~g}, 0.32 \mathrm{~mol})$ and ethyl acetoacetate $(42.15 \mathrm{~g}, 0.32 \mathrm{~mol})$ were dissolved in $130 \mathrm{~mL}$ of 1,4-dioxane. Then, $9.7 \mathrm{~mL}$ of concentrated sulfuric acid (182 mmol) were added dropwise and stirred for $3 \mathrm{~h}$ at $65{ }^{\circ} \mathrm{C}$. The reaction was cooled down to room temperature and the white precipitate was filtered and washed with hexane to obtain pure 7-hydroxy-4-methylcoumarin (HMC). Later, HMC (4 g, $22.7 \mathrm{mmol}$ ) was poured in a two-neck round-bottom flask and dissolved in $20 \mathrm{~mL}$ of DMF. Then, 2-bromoethanol (4.3 g, $34.4 \mathrm{mmol}$ and potassium carbonate $(6.3 \mathrm{~g}, 45.6 \mathrm{mmol})$ was added under stirring. The reaction mixture was stirred for $24 \mathrm{~h}$ at $88^{\circ} \mathrm{C}$, then cooled down and poured into ice water; the crude product was filtered and recrystallized twice in ethyl acetate to obtain $35.2 \mathrm{~g}$ of HEOMC (yield ca. $50 \%$ ).

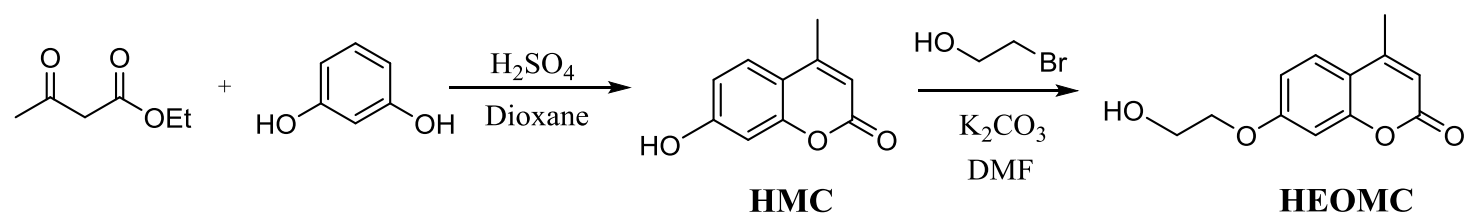

${ }^{1} \mathrm{H}$ NMR (400 MHz, $\left.\mathrm{CDCl}_{3}, \mathrm{ppm}\right): 7.51(\mathrm{~d}, 1 \mathrm{H} ; \mathrm{J}=8.8 \mathrm{~Hz}), 6.88(\mathrm{dd}, 1 \mathrm{H} ; \mathrm{J} 1=8.8 \mathrm{~Hz}, \mathrm{~J} 2$ $=2.8 \mathrm{~Hz}), 6.83(\mathrm{~d}, 1 \mathrm{H}, \mathrm{J}=2.8 \mathrm{~Hz}), 6.15(\mathrm{~d}, 1 \mathrm{H}, \mathrm{J}=1.2 \mathrm{~Hz}), 4.15(\mathrm{t}, 2 \mathrm{H}, \mathrm{J}=4.4 \mathrm{~Hz}), 4.02$ $(\mathrm{q}, 2 \mathrm{H}, \mathrm{J}=4.9 \mathrm{~Hz}), 2.40(\mathrm{~d}, 3 \mathrm{H}, \mathrm{J}=1.2 \mathrm{~Hz}), 2.09(\mathrm{t}, 1 \mathrm{H}, \mathrm{J}=6.0 \mathrm{~Hz}, \mathrm{OH})$. FTIR: $v\left(\mathrm{~cm}^{-1}\right)$ $=3427,2954,1704,1621,1554,1388,1370,1295,1272$, 1268, 1153, 1074, 1042, 892, $893,867,846,817,752,573,526,441$.

\subsection{Synthesis of HEOMC-succinic acid (HEOMCO)}

The synthesis of the coumarin derivative was achieved by following the procedure described in a previous work [13]. In a rounded flask, HEOMC (2.10 g, $9.52 \mathrm{mmol})$ was dissolved in $25 \mathrm{~mL}$ of DCM and TEA $(5.32 \mathrm{~mL}, 38.1 \mathrm{mmol})$ was added. In another flask, succinic anhydride (1.52 g, $14.26 \mathrm{mmol})$ and DMAP (57.5 mg, $0.47 \mathrm{mmol})$ were 
dissolved in $30 \mathrm{~mL}$ of DCM. The solution of HEOMC was poured into the second flask and the mixture was stirred at room temperature for 72 hours. The solution was filtered, washed with a $5 \% \mathrm{HCl}$ solution and purified by recrystallization in ethanol to obtain $2.44 \mathrm{~g}$ (yield ca. $80 \%$ ) of HEOMCO.<smiles>Cc1cc(=O)oc2cc(OCCO)ccc12</smiles>

HEOMC

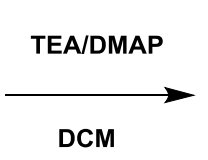<smiles>Cc1cc(=O)oc2cc(OCCOC(=O)CCC(=O)O)ccc12</smiles>

HEOMCO

${ }^{1} \mathrm{H}$ NMR (400 MHz, DMSO, ppm): $\delta 7.70$ (d, J = 8.7 Hz, 1H), $7.05-6.96(\mathrm{~m}$, 2H), $6.23(\mathrm{~d}, \mathrm{~J}=1.5 \mathrm{~Hz}, 1 \mathrm{H}), 4.42-4.27(\mathrm{~m}, 4 \mathrm{H}), 2.41(\mathrm{~d}, \mathrm{~J}=1.3 \mathrm{~Hz}, 3 \mathrm{H}) .{ }^{13} \mathbf{C}$ NMR (101 MHz, DMSO, ppm): $\delta$ 173.8, 172.6, 161.7, 160.6, 155.1, 153.8, 127.0, 113.8, 112.9, 111.8, 101.9, 67.0, 62.8, 29.1, 18.6. Electron-ionization mass spectroscopy (EIMS): $\mathrm{m} / \mathrm{z}$ calculated for $\mathrm{C}_{16} \mathrm{H}_{16} \mathrm{O}_{7}[\mathrm{M}+\mathrm{H}]^{+}: 320.0896$, found: 320.0902 . FTIR: $v\left(\mathrm{~cm}^{-1}\right)$ $=3098,3025,2993,2955,2931,1726,1656,1606,1556,1391,1369,1339,1301$, 1208, 1148, 1080, 1029, 983, 905, 875, 851, 833, 795, 747, 705, 667.

\subsection{Synthesis of HEOMC-phthalic acid (HEOMC-PH)}

In a rounded flask, $5 \mathrm{~g}$ of HEOMC (22.70 mmol) and $4.7 \mathrm{~mL}$ of TEA (34.05 mmol, 1.5 eq.) were dissolved in $100 \mathrm{~mL}$ of anhydrous THF under Argon atmosphere. In another two-necked rounded flask provided with a condenser, $5 \mathrm{~g}$ of phthalic anhydride (34.05 mmol, 1.5 eq.) and $138 \mathrm{mg}$ of DMAP (1.13 mmol, 0.05 eq.) were dissolved in $30 \mathrm{~mL}$ of anhydrous THF. Afterward, the solution of HEOMC was added with a syringe over the phthalic solution and the mixture was stirred at reflux for 72 hours. The mixture was cooled down to room temperature and the salt of TEA was filtered. Then, the solution was concentrated, washed with aqueous $5 \% \mathrm{HCl}$ and extracted with DCM. The product was dried, concentrated and purified by precipitation in cold DCM to obtain $6.2 \mathrm{~g}$ (yield ca. 78\%) of a white solid (HEOMC-PH).<smiles>Cc1cc(=O)oc2cc(OCCO)ccc12</smiles>

HEOMC<smiles>O=C1OC(=O)c2ccccc21</smiles>

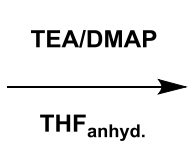

THF anhyd.<smiles>Cc1cc(=O)oc2cc(OCCOC(=O)c3ccccc3C(=O)O)ccc12</smiles>

HEOMC-PH 
${ }^{1} \mathrm{H}$ NMR (500 MHz, DMSO-d6, ppm): $\delta 13.28$ (s, 1H), $7.82-7.73(\mathrm{~m}, 1 \mathrm{H})$, $7.66(\mathrm{~d}, J=8.8 \mathrm{~Hz}, 1 \mathrm{H}), 7.65-7.61(\mathrm{~m}, 3 \mathrm{H}), 7.02(\mathrm{~d}, J=2.4 \mathrm{~Hz}, 1 \mathrm{H}), 6.99$ (dd, $J=8.8$, $2.5 \mathrm{~Hz}, 1 \mathrm{H}), 6.20(\mathrm{~d}, J=1.3 \mathrm{~Hz}, 1 \mathrm{H}), 4.64-4.55$ (m, 2H), $4.42-4.38$ (m, 2H), 2.38 (s, 3H). ${ }^{13} \mathrm{C}$ NMR (101 MHz, DMSO-d6, ppm): $\delta 167.8,167.5,161.2,160.1,154.7,153.3$, 132.2, 131.9, 131.4, 131.1, 129.0, 128.2, 126.5, 113.3, 112.4, 111.3, 101.4, 66.3, 18.1 . Electron-ionization mass spectroscopy (EI-MS): $\mathrm{m} / \mathrm{z}$ calculated for $\mathrm{C}_{20} \mathrm{H}_{16} \mathrm{O}_{7}[\mathrm{M}+\mathrm{H}]^{+}$: 368.0896, found: 368.0889. FTIR: $v\left(\mathrm{~cm}^{-1}\right)=1719$, 1675, 1614, 1394, 1285, 1269, $1213,1134,1075,880,675$.

\subsection{Synthesis of EVOH-HEOMC (ENH) copolymer}

\subsubsection{Modification of EVOH with $\boldsymbol{p}$-nitrophenyl cloroformate: EN}

EVOH was activated by following the procedure described by Sánchez-Chaves et al. [22]. Firstly, $5 \mathrm{~g}(135 \mathrm{mmol})$ of EVOH were dissolved in $170 \mathrm{~mL}$ of NMP at $80^{\circ} \mathrm{C}$ in a double-walled reactor and then cooled to $0{ }^{\circ} \mathrm{C}$. Afterwards, $9.3 \mathrm{~mL}(114 \mathrm{mmol})$ of pyridine and $23 \mathrm{~g}$ (114 mmol) of $p$-nitrophenyl chloroformate were added and stirred for $24 \mathrm{~h}$. The modified EVOH was isolated by precipitation with ethanol and purified by reprecipitation from DMF in ethanol. Then, the product $(\mathrm{EN})$ was dried at vacuum in the presence of phosphorous pentoxide to obtain a white solid with a substitution degree (SD) of $99 \%$.

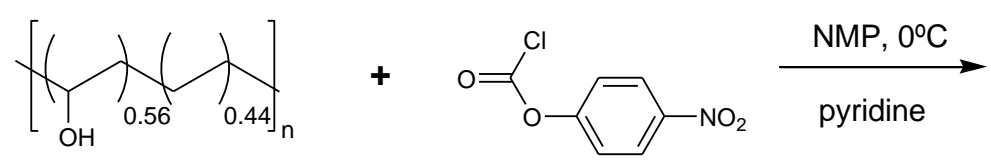

EVOH

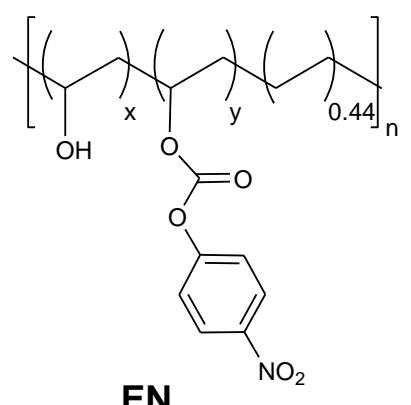

EN: ${ }^{1} \mathrm{H}$ NMR (DMSO-d6, $\left.500 \mathrm{MHz}\right): \delta 8.07$ (s, 2H), $7.41-7.26(\mathrm{~m}, 2 \mathrm{H}), 5.16-$ $4.76(\mathrm{~s}, 1 \mathrm{H}), 2.19-1.26(\mathrm{~m}, 6 \mathrm{H}) .{ }^{13} \mathrm{C}$ NMR (DMSO-d6, $\left.126 \mathrm{MHz}\right): \delta 155.1,152.2$, 144.9, 126.1, 122.3, 80.1, 78.1, 76.1, 74.4, 72.7, 37.8, 37.3, 33.6, 32.8, 28.6, 24.4, 20.1. FTIR: $v\left(\mathrm{~cm}^{-1}\right)=3419,2931,1755,1669,1616,1594,1522,1493,1347,1260,1206$, $1164,1090,1050,1011,858,760,722,681$. 


\subsubsection{Incorporation of HEOMC to EN}

A mixture of HEOMC (10.6 g, $48.2 \mathrm{mmol})$ and TEA (10 mL, $72.3 \mathrm{mmol})$ was incorporated to a solution of EN (5.6 g, $24.1 \mathrm{mmol}$ of reactive groups) in $280 \mathrm{~mL}$ of DMF. Catalyst DMAP (147 mg, $1.2 \mathrm{mmol}$ ) was added to the mixture and stirred $72 \mathrm{~h}$ at $70{ }^{\circ} \mathrm{C}$. The solution was cooled at r.t. and precipitated over distillated water. The product was purified by precipitation from DCM in methanol to obtain $4.4 \mathrm{~g}$ of a lightyellow solid with a $62 \%$ of SD.
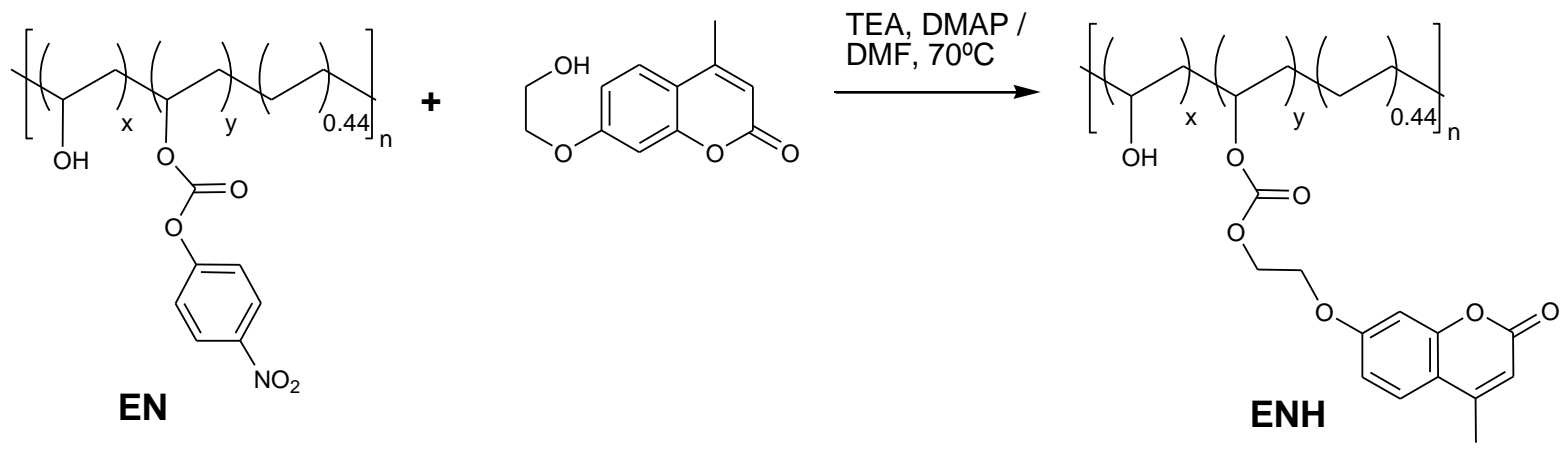

ENH: ${ }^{1} \mathrm{H}$ NMR (DMSO-d6, $\left.500 \mathrm{MHz}\right): \delta 7.59$ (s, 1H), 6.89 (s, 2H), $6.13(\mathrm{~s}, 1 \mathrm{H})$, $4.89-4.62(\mathrm{~m}, 1 \mathrm{H}), 4.44(\mathrm{~s}, 2 \mathrm{H}), 4.31(\mathrm{~s}, 2 \mathrm{H}), 2.35(\mathrm{~s}, 3 \mathrm{H}), 2.07-0.99(\mathrm{~m}, 6 \mathrm{H}) .{ }^{13} \mathrm{C}$ NMR $\left(\mathrm{CDCl}_{3}, 126 \mathrm{MHz}\right): \delta 160.8,159.5,154.3,153.8,152.5,125.8,113.1,111.8$, 111.0, 101.1, 66.1, 65.2, 34.5, 33.1, 28.4, 20.6, 17.5. FTIR: $v\left(\mathrm{~cm}^{-1}\right)=2928,1713,1611$, 1510, 1389, 1250, 1200, 1147, 1070, 1013, 989, 846, 784, 731, 704.

\subsection{Synthesis of EVOH-SUCCINIC-HEOMC (ESH)}

\subsubsection{Modification of EVOH with succinic anhydride (ES)}

In a two-necked rounded flask, $5 \mathrm{~g}(135 \mathrm{mmol})$ of EVOH were dissolved in 100 $\mathrm{mL}$ of DMSO at $80{ }^{\circ} \mathrm{C}$. The mixture was cooled at room temperature and $14 \mathrm{~g}$ (151 mmol) of succinic anhydride, $10.6 \mathrm{~mL}(135 \mathrm{mmol})$ of TEA and $200 \mathrm{mg}(1.6 \mathrm{mmol})$ of DMAP were added. The mixture was stirred for 5 days until it changed to dark and then was precipitated over distillated water and purified by precipitation from THF in hexane to obtain $12.4 \mathrm{~g}$ of a dark solid with SD of $89 \%$. The modified copolymer was dissolved in $200 \mathrm{~mL}$ of THF to avoid the crosslinking. 


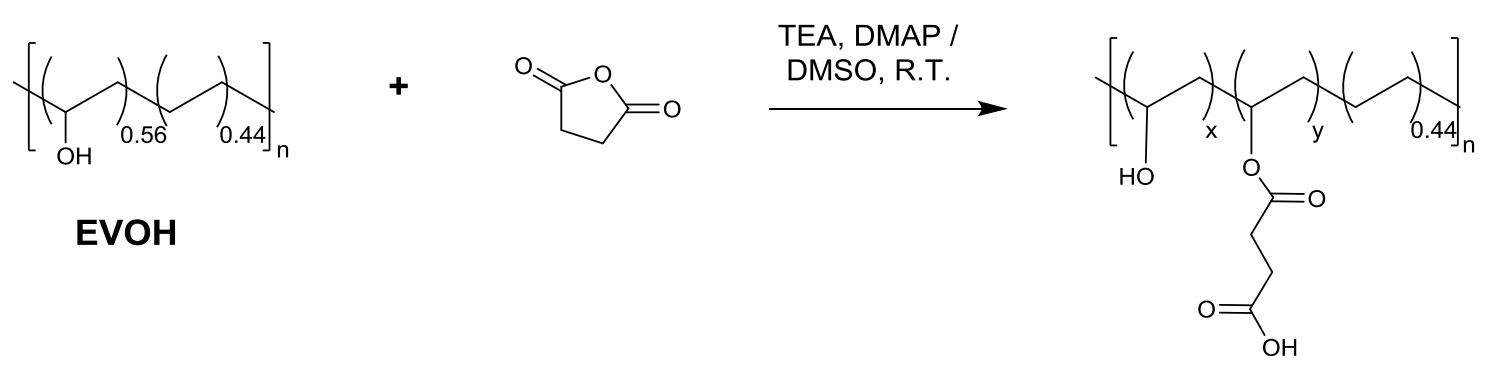

ES

ES: ${ }^{1} \mathrm{H}$ NMR (DMSO-d6, $\left.500 \mathrm{MHz}\right): \delta 12.15$ (s, 1H), 4.77 (s, 1H), $2.50-2.38$ $(\mathrm{m}, 4 \mathrm{H}), 1.73$ (s, 2H), 1.42 (s, 2H), 1.18 (s, 2H). ${ }^{13} \mathrm{C}$ NMR (DMSO-d6, $\left.126 \mathrm{MHz}\right): \delta$ 173.5, 172.3, 171.9, 67.1, 38.3, 37.9, 28.9, 25.2. FTIR: $v\left(\mathrm{~cm}^{-1}\right)=2929,1707,1408$, $1379,1159,992,953,828$.

\subsubsection{Incorporation of HEOMC to ES}

$7 \mathrm{~g}(80 \mathrm{mmol})$ of ES were previously dissolved in $70 \mathrm{~mL}$ of THF and were added to $250 \mathrm{~mL}$ of DMF. After that, $11.8 \mathrm{~g}$ (54 mmol) of HEOMC, $13.8 \mathrm{~g}$ (67 mmol) of DCC and catalyst DMAP were added to the solution under stirring at $60^{\circ} \mathrm{C}$ for $48 \mathrm{~h}$. Then, the mixture was cooled to room temperature, precipitated over distillated water and purified by precipitation from DCM in methanol. The modified copolymer was dried at vacuum to obtain $10.1 \mathrm{~g}$ of a white solid with a SD of $55 \%$.
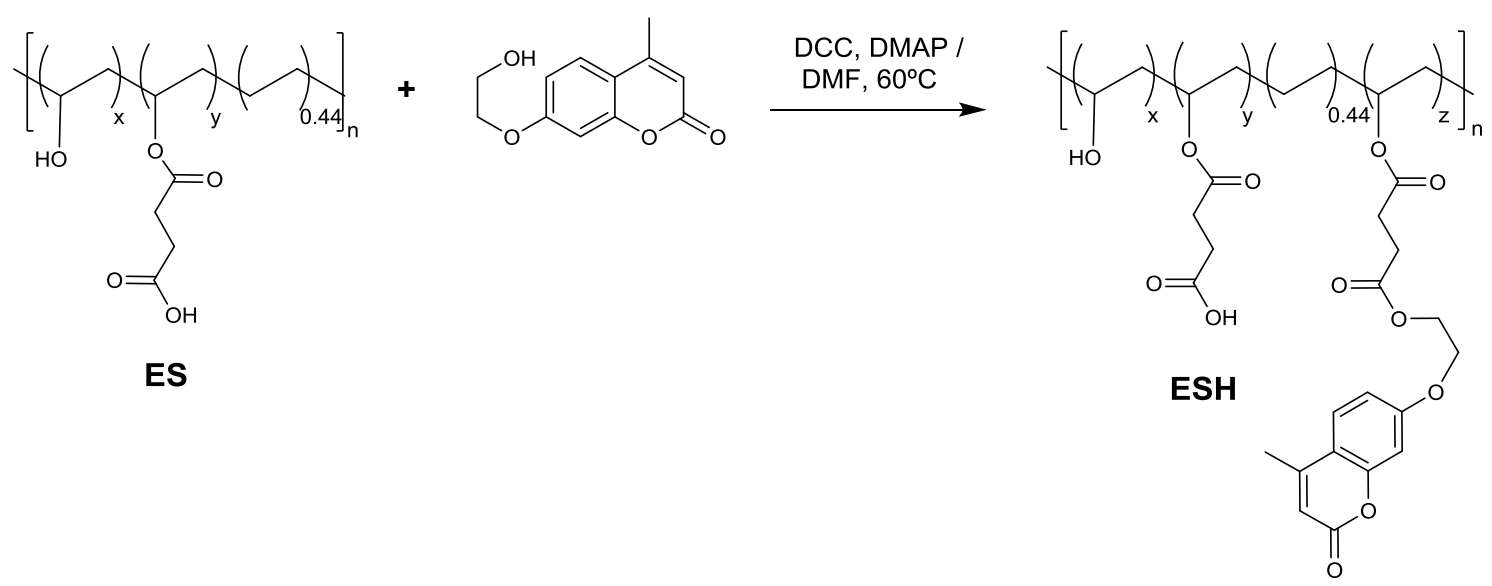

ESH: ${ }^{1} \mathrm{H}$ NMR (DMSO-d6, $\left.500 \mathrm{MHz}\right): \delta 8.16(\mathrm{~s}, 1 \mathrm{H}), 7.60(\mathrm{~s}, 1 \mathrm{H}), 6.89(\mathrm{~s}, 2 \mathrm{H})$, $6.14(\mathrm{~s}, 1 \mathrm{H}), 4.76-4.69(\mathrm{~m}, 1 \mathrm{H}), 4.35$ (s, 2H), 4.25 (s, 2H), $2.56-2.29$ (m, 7H), $1.76-$ 1.05 (m, 6H). ${ }^{13} \mathrm{C}$ NMR (DMSO-d6, $126 \mathrm{MHz}$ ): $\delta$ 171.8, 169.4, 161.1, 159.9, 154.6, 153.1, 126.3, 113.2, 112.2, 111.2, 101.2, 66.4, 62.4, 32.4, 31.6, 30.1, 29.4, 29.1, 28.7, 28.5, 25.4, 25.1, 24.5, 18.0. FTIR: $v\left(\mathrm{~cm}^{-1}\right)=2928,2854,1724,1658,1612,1525,1388$, 1369, 1345, 1263, 1146, 1070, 1013, 986, 847, 808, 732, 704. 


\subsection{Synthesis of EVOH-PHTHALIC-HEOMC (EPH)}

\subsubsection{Modification of EVOH with phthalic anhydride (EP)}

$5 \mathrm{~g}(135 \mathrm{mmol})$ of EVOH were dissolved in $200 \mathrm{~mL}$ of DMF at $80^{\circ} \mathrm{C}$, the temperature was cooled down to $60{ }^{\circ} \mathrm{C}$. Then, $16.8 \mathrm{~g}(113 \mathrm{mmol})$ of phthalic anhydride, $16 \mathrm{~mL}$ (113 mmol) of TEA and catalyst DMAP were added. After $2 \mathrm{~h}$, the product was precipitated over distillated water and further purified by re-precipitation from a mixture of acetone/methanol 1/1 over distillated water. A white solid was obtained and dried at vacuum (10.9 $\mathrm{g}$ with a substitution degree of $98 \%)$.
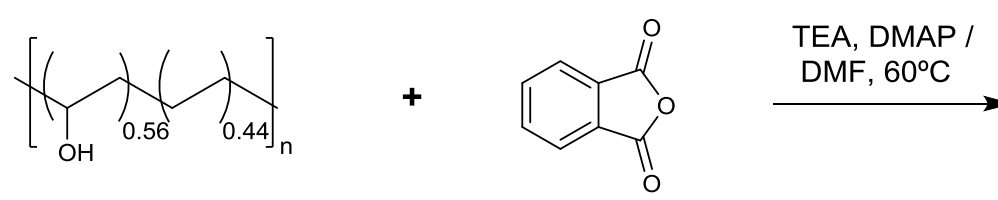

EVOH

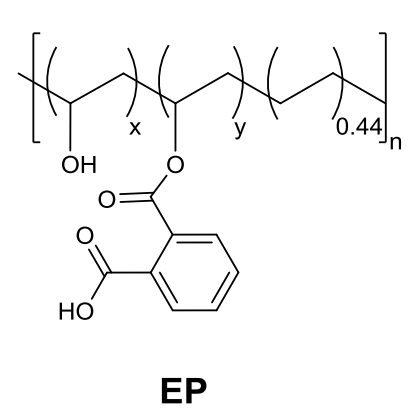

EP: ${ }^{1} \mathrm{H}$ NMR (DMSO-d6, $500 \mathrm{MHz}$ ): $\delta 13.09$ (s, 1H), $7.72-7.32$ (m, 4H), 5.27 - 4.95 (m, 1H), 2.00 - $1.18(\mathrm{~m}, 6 \mathrm{H}) .{ }^{13} \mathrm{C}$ NMR (DMSO-d6, $\left.126 \mathrm{MHz}\right): \delta 167.7,166.7$, $132.4,131.6,130.7,130.3,128.5,127.7,74.7,71.4,68.3,37.0,33.0,28.9,24.5,24.2$, 20.1. FTIR: $v\left(\mathrm{~cm}^{-1}\right)=2928,1701,1599,1579,1283,1261,1127,1070,1039,791,742$, 705,676 .

\subsubsection{Incorporation of HEOMC to EP}

In a two necked rounded flask, $5.5 \mathrm{~g}(45 \mathrm{mmol})$ of EP and $6.7 \mathrm{~g}(31 \mathrm{mmol})$ of HEOMC were dissolved in $125 \mathrm{~mL}$ of anhydrous DMF. In another flask, $6.3 \mathrm{~g} \mathrm{(31}$ mmol) of DCC and catalyst DMAP were dissolved in $20 \mathrm{~mL}$ of anhydrous DMF. The solution was incorporated over the first flask with a syringe and was stirred at $60{ }^{\circ} \mathrm{C}$ for $24 \mathrm{~h}$. The solution was precipitated over distillated water; the solid obtained was dried with phosphorous pentoxide and purified by dissolution in DCM and precipitation over methanol twice. The white solid obtained was dried at vacuum $(8.9 \mathrm{~g}$ with a substitution degree of $40 \%)$. 

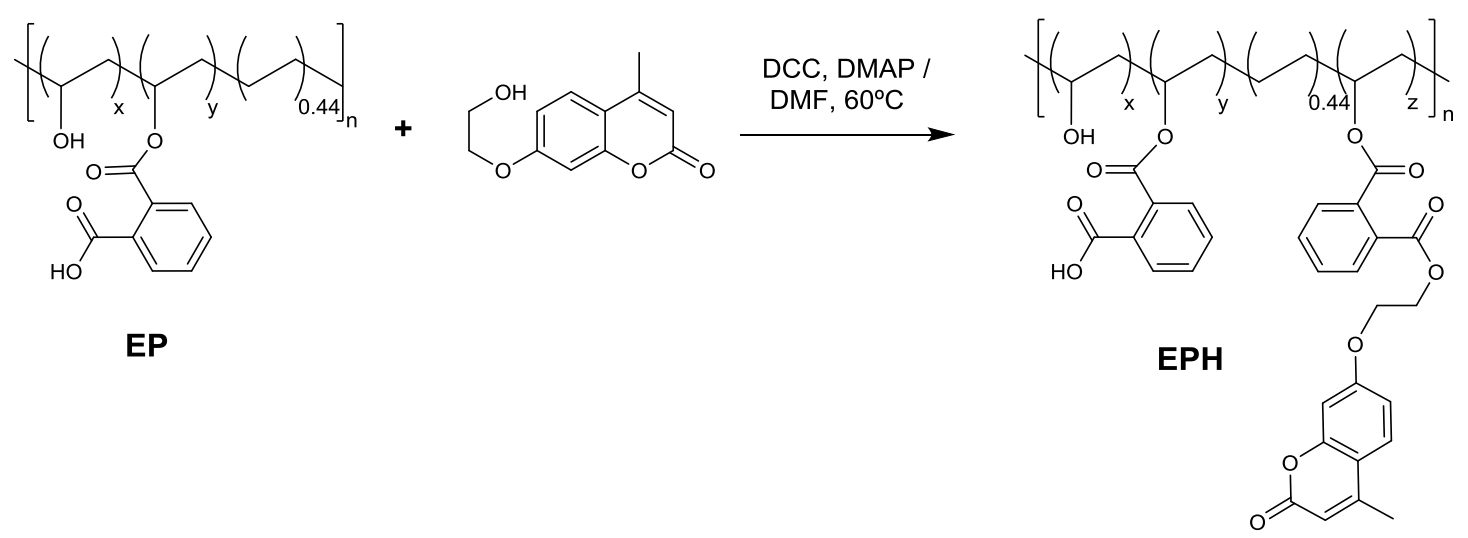

EPH: ${ }^{1} \mathrm{H}$ NMR $(500 \mathrm{MHz}): \delta 7.97-7.11(\mathrm{~m}, 5 \mathrm{H}), 6.84(\mathrm{~s}, 2 \mathrm{H}), 6.09(\mathrm{~s}, 1 \mathrm{H})$, $5.47-4.75(\mathrm{~m}, 1 \mathrm{H}), 4.71-4.03(\mathrm{~m}, 4 \mathrm{H}), 2.25(\mathrm{~s}, 3 \mathrm{H}), 2.05-0.25(\mathrm{~m}, 6 \mathrm{H}) .{ }^{13} \mathrm{C} \mathrm{NMR}$ (DMSO, 126 MHz): $\delta$ 167.2, 166.6, 161.5, 160.4, 155.0, 153.1, 139.2, 131.8, 129.0, 126.7, 113.7, 112.7, 111.7, 101.6, 75.7, 72.9, 70.0, 66.7, 63.9, 34.0, 31.6, 30.5, 29.5, 26.0, 25.3, 24.4, 18.4. FTIR: $v\left(\mathrm{~cm}^{-1}\right)=2929,2855,1713,1650,1613,1512,1448$, $1389,1367,1345,1259,1135,1068,848,770,740,706$.

Finally, all materials were processed into films by compression molding in a hot press (Dr. COLLIN $200 \times 200)$ at $100{ }^{\circ} \mathrm{C}$ by using a film mold $\left(50 \times 50 \mathrm{~mm}^{2}\right) .{ }^{1} \mathrm{H}-\mathrm{NMR}$ and ${ }^{13} \mathrm{C}$-NMR spectra are depicted in the Supporting Information (Fig. S1 to S17).

\subsection{Characterization techniques}

All molded compressed EVOH copolymers were elucidated by ${ }^{1} \mathrm{H}$ NMR and ${ }^{13} \mathrm{C}$-NMR spectra at $500 \mathrm{MHz}$ in a Varian System 500 spectrometer by using deuterated dimethyl sulfoxide (ca. 8\% w/v). Fourier transform infrared (FTIR) spectra were acquired with a Spectrum One FTIR spectrometer with a resolution of $4 \mathrm{~cm}^{-1}$ and 16 accumulation scans (Perkin-Elmer Co., Norwalk, CT, USA) in the $4000-650 \mathrm{~cm}^{-1}$ region at room temperature. The modification degree of EVOH copolymers was also confirmed by UV spectra recorded in a NanoDrop one (Thermo Fisher Scientific). Coumarin modified EVOH copolymers were irradiated at $365 \mathrm{~nm}$ with $5 \times 8 \mathrm{~W} 365 \mathrm{~nm}$ UV lamps for 210 min to produce the coumarin [2+2] cycloaddition reaction, while they were irradiated at $254 \mathrm{~nm}$ with $5 \times 8 \mathrm{~W} 254 \mathrm{~nm}$ - UV lamps during $180 \mathrm{~s}$ for the photocleavage reaction. Thin copolymer films were casted over the external surface of a quartz cell and the UV spectra were acquired with a Perkin Elmer Lambda 35 UV/VIS spectrometer (Norwalk, CT, USA) from 400 to $200 \mathrm{~nm}$. The yield of photo-dimerization 
reaction was obtained from the absorbance at $320 \mathrm{~nm}$ (A 320) using the Equation 1 [23]:

$$
\text { Photo }- \text { dimerization }(\%)=\frac{A 320_{0}-A 320_{f}}{A 320_{0}} \times 100
$$

\section{Equation (1)}

$\mathrm{A} 320_{0}$ and $\mathrm{A} 320_{\mathrm{f}}$ are the absorbance values measured at $320 \mathrm{~nm}$ before and after the irradiation at $t$ time, respectively.

Glass transition $\left(\mathrm{T}_{\mathrm{g}}\right)$ and melting $\left(\mathrm{T}_{\mathrm{m}}\right)$ temperatures were determined by Differential Scanning Calorimetry (DSC). Measurements were performed with a TA Instruments DSC Q2000 (New Castle, DE, USA) under nitrogen atmosphere (50 $\mathrm{mL} / \mathrm{min})$. Samples were sealed in aluminum pans and heated from -80 to $100{ }^{\circ} \mathrm{C}$ at 10 ${ }^{\circ} \mathrm{C} / \mathrm{min}$. The degree of crystallinity $\left(\mathrm{X}_{\mathrm{c}}\right)$ was calculated from the enthalpy of a $100 \%$ crystalline poly(vinyl alcohol) (PVA) (157.8 J/g) [24]. TA Instruments TGA Q500 thermal analyzer was used to perform the thermogravimetric measurements under dynamic mode using nitrogen atmosphere (flow rate of $60 \mathrm{~mL} / \mathrm{min}$ ). Samples were heated from room temperature to $700{ }^{\circ} \mathrm{C}$ at a heating rate of $10{ }^{\circ} \mathrm{C} / \mathrm{min}$. The initial degradation temperatures $\left(\mathrm{T}_{0}\right)$ were obtained at $5 \%$ of mass loss and temperatures at the maximum degradation rate $\left(\mathrm{T}_{\max }\right)$ were obtained from the first derivative of the TGA curves (DTG). Microindentation measurements were obtained with a Vickers indentator attached to Leitz microhardness $(\mathrm{MH})$ tester. Experiments were undertaken at $22{ }^{\circ} \mathrm{C}$ with contact load of $980 \mathrm{~N}$ and a contact time of $25 \mathrm{~s}$. MH (in MPa) were calculated according to the relationship: $\mathrm{MH}=2 \sin 68 \mathrm{P} / \mathrm{d}^{2}$, where $\mathrm{P}(\mathrm{in} \mathrm{N})$ is the contact load and $\mathrm{d}$ (in $\mathrm{mm}$ ) is the diagonal length of the projected indentation area.

Surface wettability of the films was obtained with a KSV Theta goniometer by static water contact angle (WCA) measurements in contact mode. The volume of the droplets was 7.0 $\mu \mathrm{L}$ and the contact angle was determined as the average value of 4 drops of distilled water randomly deposited with a syringe the film surface. The surface of the films was observed by scanning electron microscopy (SEM) using a Philips XL30 microscope with an acceleration voltage of $25 \mathrm{kV}$. Prior to SEM observation, the films were coated with gold. Antifouling properties of EVOH derivatives were obtained by immersing the films $(1 \times 1 \mathrm{~cm})$ in solutions $0.01 \mathrm{M}$ of bovine serum albumin-fluorescein isothiocyanate conjugate (BSA-FITC) in Trizma hydrochloride buffer solution for 3 hours at $25^{\circ} \mathrm{C}$. Then, the film was removed from the solution and the unbound protein concentration was analyzed in the resultant solution by fluorescence spectroscopy in a 
Synergy HTX Multi-Mode Reader spectrophotometer (Bio-Tek) at an excitation wavelength of $480 \mathrm{~nm}$ and an emission wavelength of $525 \mathrm{~nm}$. Briefly, $100 \mu \mathrm{L}$ of each solution was placed in a 96-well round-bottom microplate. All films were analyzed in triplicate, and blank experiments were also performed with the Trizma buffer solutions. The fluorescence intensity of each sample was measured and the data were converted to concentration of unbound protein using the corresponding standard curve. From this data, the amount of BSA-FITC adsorbed onto the surface of the film was calculated by subtracting the unbound concentration from the initial concentration and the represented in $\mathrm{ng} \mathrm{cm}^{-1}$.

\section{Results and discussion}

The different synthetic routes followed to obtain EVOH containing coumarin groups are represented in Scheme 1. Notice that although all the obtained coumarin derivatives presented similar coumarin group the chemical structure of the resulting copolymers significantly differs.

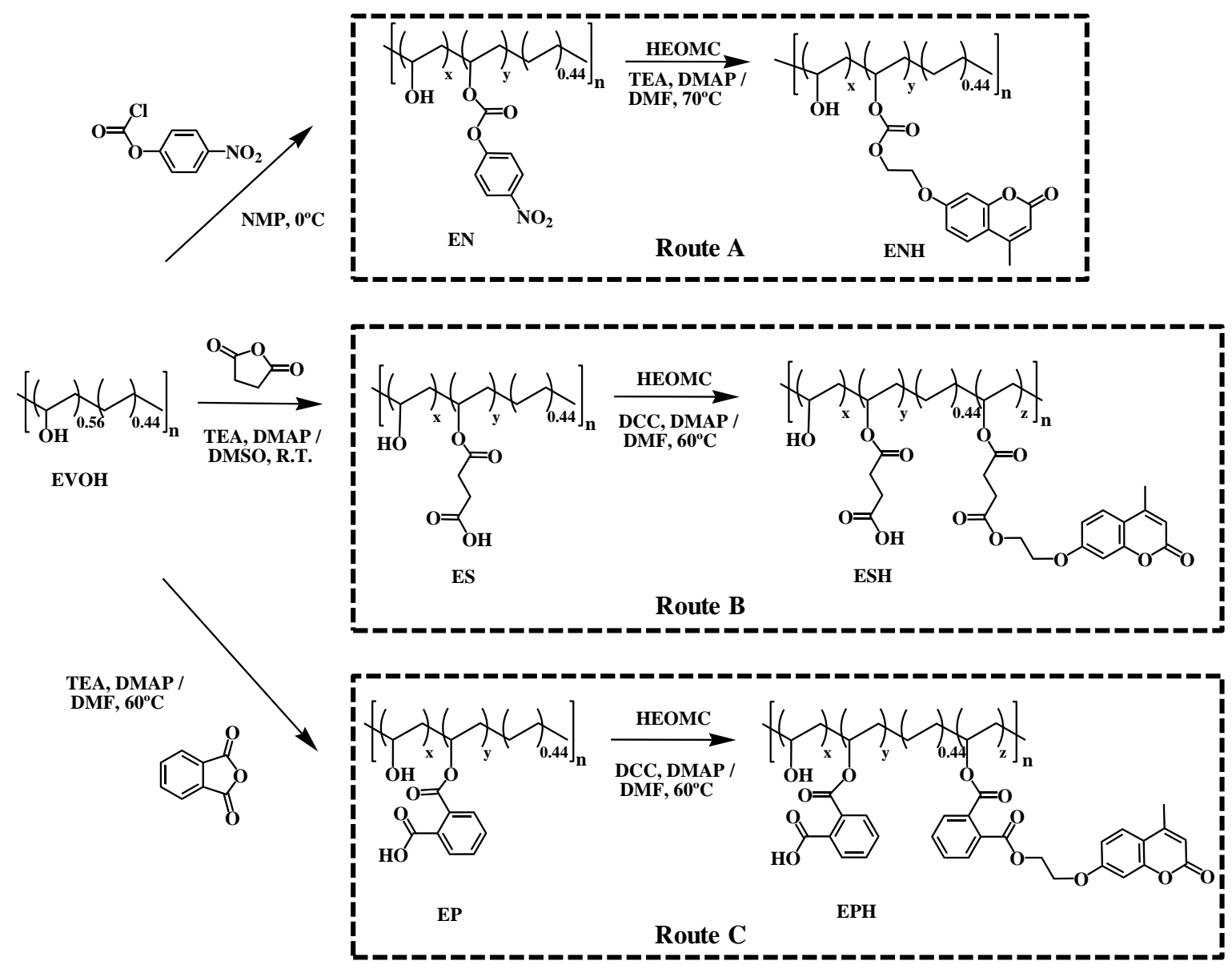

Scheme 1. Synthetic routes of modified EVOH copolymers. 


\subsection{Characterization of the copolymer ENH obtained by route A}

EN modified copolymer was characterized by FTIR, ${ }^{1} \mathrm{H}$ and ${ }^{13} \mathrm{C}-\mathrm{NMR}$. The most characteristic IR bands are shown in Fig. 1A. Coumarin presents typical absorption bands at 1720 and $1615 \mathrm{~cm}^{-1}$, belonging to $\mathrm{C}=\mathrm{O}$ and $\mathrm{C}=\mathrm{C}$ lactone stretching vibration, respectively. The $\mathrm{C}-\mathrm{O}$ ester stretching vibration band appears at 1278 and $1070 \mathrm{~cm}^{-1}$ and $\mathrm{C}-\mathrm{H}$ aromatic out of plane bending vibration appears at $840 \mathrm{~cm}^{-1}$ [21]. The most characteristic signals of EVOH appear at $1440 \mathrm{~cm}^{-1}$ (methylene asymmetric stretch), $1330 \mathrm{~cm}^{-1}$ (methine asymmetric stretch), $1087 \mathrm{~cm}^{-1}$ (C-O stretch) and $840 \mathrm{~cm}^{-1}$ (deformation of C-H out of plane). The hydroxyl stretch $\left(3320 \mathrm{~cm}^{-1}\right)$ and the methylene anti-symmetric stretch $\left(2900 \mathrm{~cm}^{-1}\right)$ bands are not shown in the Fig. 1-A.

Fig. 1-B shows ${ }^{1} \mathrm{H}-\mathrm{NMR}$ signals of EN as well as those of HEOMC and EVOH. Aromatic signals of HEOMC appear at 7.7, 6.9, and $6.2 \mathrm{ppm}$, proton of hydroxyl group at $4.9 \mathrm{ppm}$, the methylene groups at 4.1 and $3.7 \mathrm{ppm}$ and the methyl group at $2.4 \mathrm{ppm}$ [13]. EVOH signals appear in three regions: from 4.1 to $4.7 \mathrm{ppm}$ (hydroxyl groups), from 3.3 to $3.9 \mathrm{ppm}$ (methine groups) and from 1.2 to $1.4 \mathrm{ppm}$ (methylene groups) [22]. These three groups of alcohol and methylene signals correspond to the isotactic, heterotactic and syndiotactic arrangement in PVA [25].
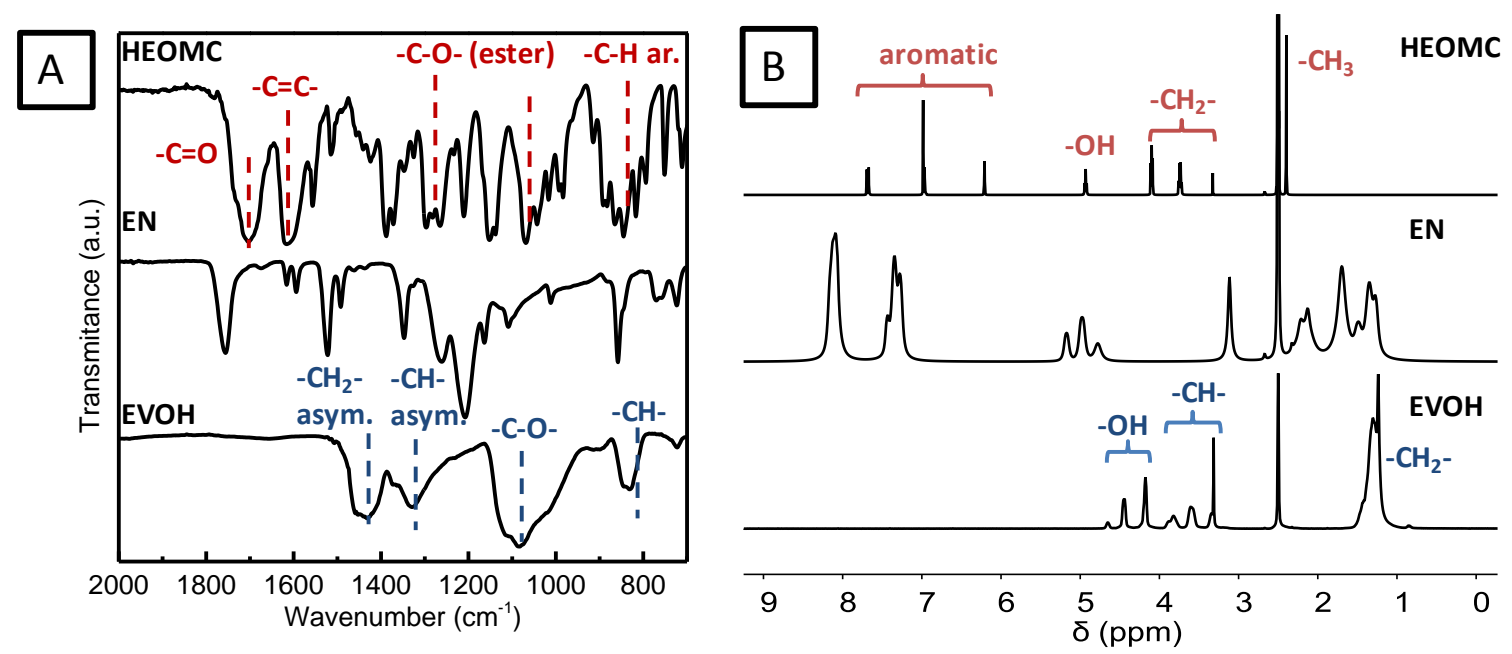

Fig. 1. FTIR (A) and ${ }^{1}$ H-NMR (B) spectra of: EVOH, EN and HEOMC.

The substitution degree (SD) of modified EVOH copolymers was calculated by using ${ }^{1} \mathrm{H}-\mathrm{NMR}$. EVOH methylene signals (between 2.1 and $0.6 \mathrm{ppm}$ ) were compared with methine signal (around $4.5 \mathrm{ppm}$ ) of modified groups to determine the SD (Equation 2) in the copolymer without coumarin (EN). As EVOH is a copolymer with 
$56 \%$ of vinyl alcohol, the methine signal is referred to 56 per each 100 repeating units. Besides, the methylene signal contains two protons, which correspond to vinyl group (56\%), and four protons of the ethylene (44\%) that are considered in the equation.

$S D_{(\text {without coumarin })}(\%)=\frac{\text { Integral of methine at } 4.5 \mathrm{ppm} \times(2 \times 0.56+4 \times 0.44)}{\text { Integral of methylene at } 2.1-0.6 \mathrm{ppm} \times 0.56}$

Equation 2

The incorporation of coumarin to the EVOH copolymer is confirmed by ${ }^{1} \mathrm{H}$ NMR, ${ }^{13} \mathrm{C}$-NMR and FTIR. In the Fig. 2 the most important ${ }^{13} \mathrm{C}-\mathrm{NMR}$ and FTIR signals are shown. The presence of the carbonyl group in the copolymer ENH, belonging to the $p$-nitrophenyl chloroformate is confirmed by the signal at $154 \mathrm{ppm}$ in the ${ }^{13} \mathrm{C}-\mathrm{NMR}$ spectrum, as can be observed in the Fig. 2A and marked with a discontinuous blue rectangle. Carbonyl group can also be distinguished by FTIR with a shoulder at 1735 $\mathrm{cm}^{-1}$ corresponding to the $\mathrm{C}=\mathrm{O}$ stretching vibration (Fig. 2B). Also, the end of reaction can be followed by FTIR (Fig. 2B), where aromatic bands at 1520 and $1350 \mathrm{~cm}^{-1}$ disappear (marked as blue discontinuous circles) and the coumarin lactone band at 1615 $\mathrm{cm}^{-1}$ appears (marked as red discontinuous circle).
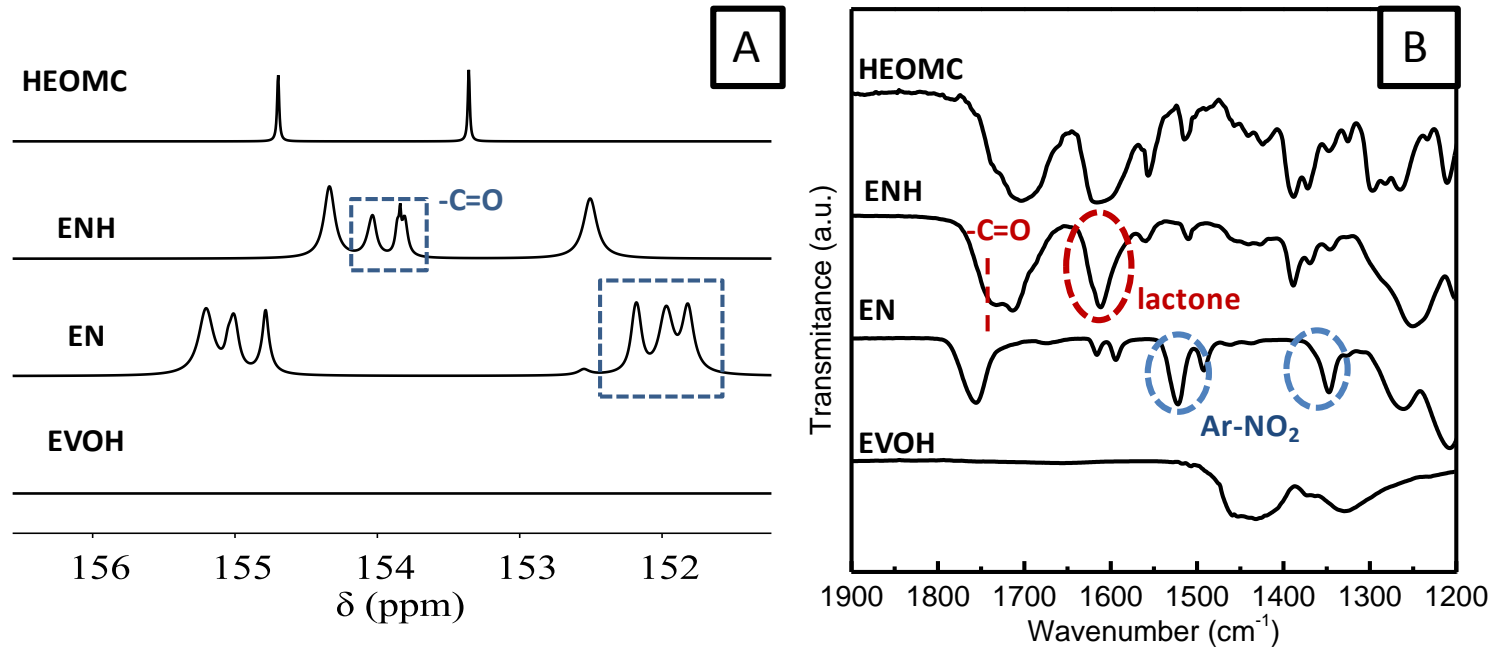

Fig. 2. ${ }^{13}$ C-NMR (A) and FTIR (B) spectra of: EVOH, EN, ENH and HEOMC.

Meanwhile, in coumarin modified copolymers (ENH, ESH and EPH) the SD was calculated by comparison of the HEOMC aromatic signal at $6.1 \mathrm{ppm}$ and the methine signal at $4.5 \mathrm{ppm}$ of modified EVOH (Equation 3). Therefore, the SD is referred to the amount of coumarin that has reacted with the modified EVOH. 


\subsection{Characterization of the copolymer ESH obtained by route B}

The modification of EVOH with succinic anhydride (ES), and subsequently modification with HEOMC (ESH) were also confirmed by ${ }^{1} \mathrm{H}-\mathrm{NMR}$ and FTIR spectroscopy (see Fig. 3). Methine signals in EVOH (3.3 to $3.9 \mathrm{ppm}$ ) are shifted to 4.8 ppm when EVOH is modified with succinic anhydride (pictured with blue discontinuous circle in Fig. 3A). The incorporation of coumarin to ES (Fig. 3A) shifts the methylene bands of HEOMC at 3.7 and $4.1 \mathrm{ppm}$ to 4.2 and $4.3 \mathrm{ppm}$ in ESH (red discontinuous circle), respectively. In addition, the methine group at $4.8 \mathrm{ppm}$ in ES is slightly affected by the incorporation of HEOMC and is shifted to $4.7 \mathrm{ppm}$ in ESH. Similarly, the FTIR spectra confirmed the successfully modification of the EVOH copolymer, obtained by this route. In the FTIR spectra (Fig. 3B marked in blue characters), the appearance of the carbonyl stretching band belonging to the dimer $\mathrm{C}=\mathrm{O}$ in carboxylic acids at $1710 \mathrm{~cm}^{-1}$ and a shoulder of ester $\mathrm{C}=\mathrm{O}$ stretch at $1725 \mathrm{~cm}^{-1}$ confirm the process [9]. In the FTIR spectra (Fig. 3B), the modification of ES with HEOMC induces the decrease of the $\mathrm{C}=\mathrm{O}$ acid dimer band. Furthermore, the presence of $\mathrm{C}=\mathrm{O}\left(1655 \mathrm{~cm}^{-1}\right)$ and $\mathrm{C}=\mathrm{C}$ lactone $\left(1615 \mathrm{~cm}^{-1}\right)$ bands of coumarin are marked in red; also a displacement in the $\mathrm{C}=\mathrm{O}$ stretching from 1705 to $1655 \mathrm{~cm}^{-1}$ is observed, triggered by hydrogen bond interaction with the carboxyl groups of unmodified ES.
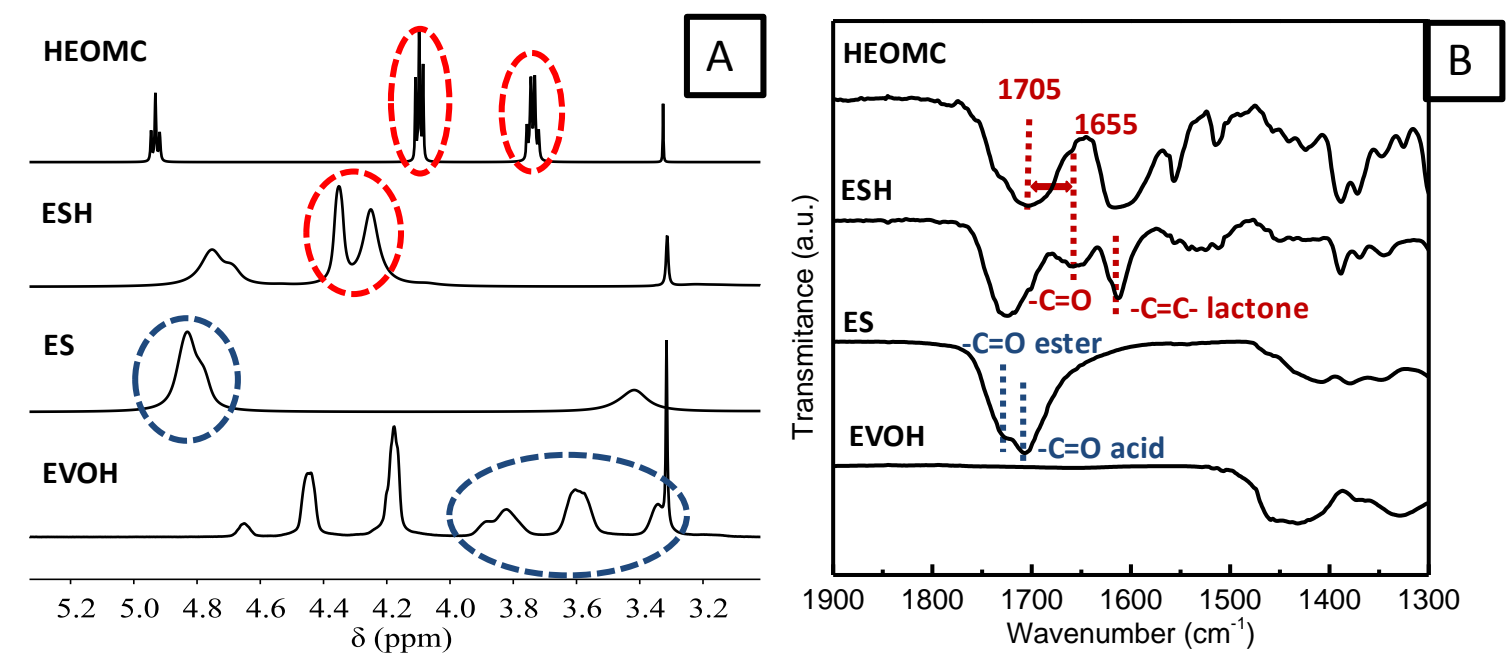

Fig. 3. ${ }^{1} \mathrm{H}-\mathrm{NMR}$ (A) and FTIR (B) spectra of: EVOH, ES, ESH and HEOMC. 


\subsection{Characterization of the copolymer EPH obtained by route $\mathrm{C}$}

Likewise, the introduction of phthalic anhydride and afterwards HEOMC into the EVOH copolymer was elucidated by ${ }^{1} \mathrm{H}-\mathrm{NMR}$ and FTIR spectroscopy. In the Fig. 4A the influence of the phthalic anhydride into the EVOH chain (EP) is shown by the presence of the methine band at $5.1 \mathrm{ppm}$ and also the aromatic protons of phthalic ring between 7.3 and 7.7 ppm (marked a with discontinuous blue circle). Moreover, in the FTIR spectrum (Fig. 4B) the presence of carbonyl vibrational strength at $1705 \mathrm{~cm}^{-1}$ is also marked.

The incorporation of HEOMC into the EP is also established by the presence of new aromatic signals of HEOMC in the ${ }^{1} \mathrm{H}-\mathrm{NMR}$ spectrum (marked with a red discontinuous circle in Fig. 4A). Moreover, the carbonyl vibrational strength of lactone coumarin bands at $1655 \mathrm{~cm}^{-1}(\mathrm{C}=\mathrm{O})$ and $1615 \mathrm{~cm}^{-1}(\mathrm{C}=\mathrm{C})$ are observed (Fig. 4B).

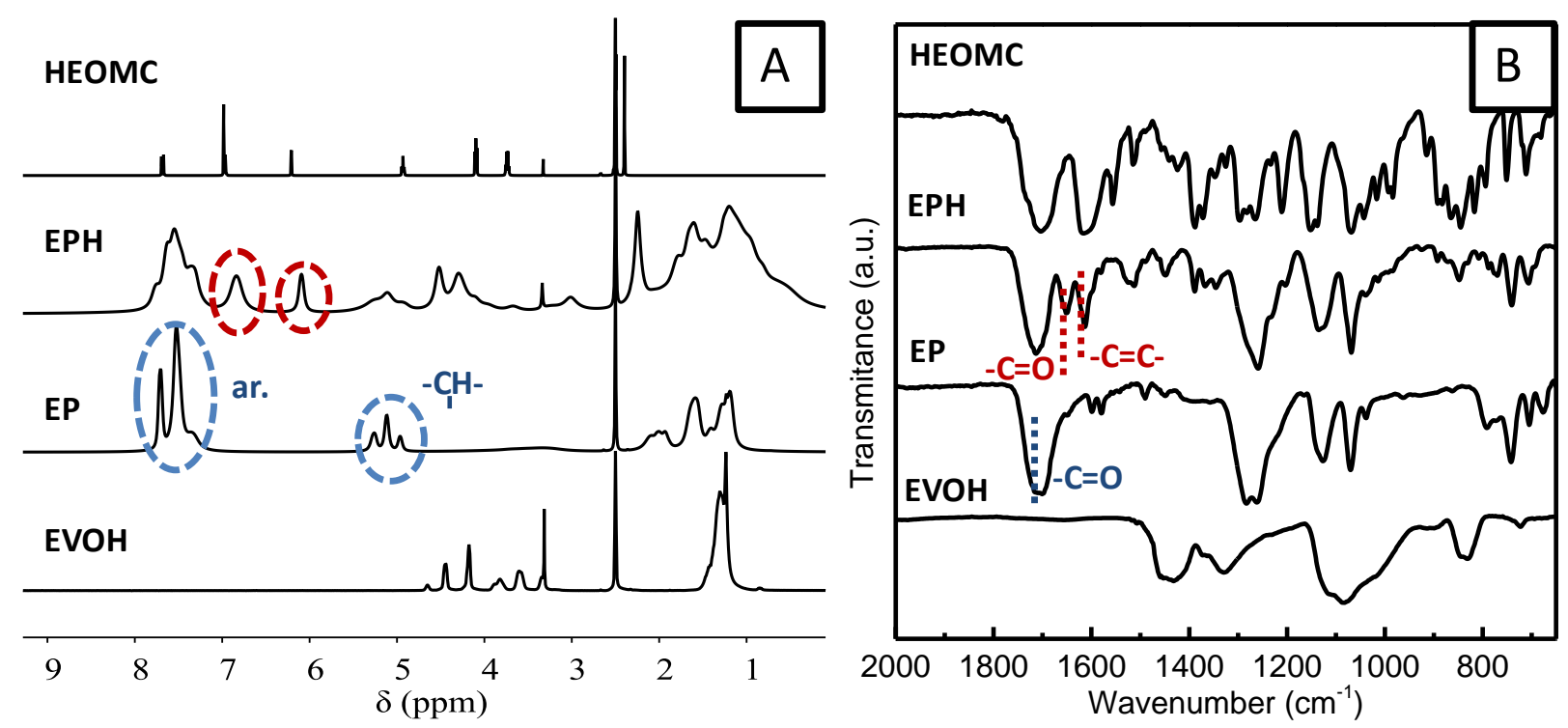

Fig. 4. ${ }^{1} \mathrm{H}-\mathrm{NMR}(\mathbf{A})$ and FTIR (B) spectra of: EVOH, EP, EPH and HEOMC.

The substitution degree of the copolymers EP and EPH were determined thought the equation $\mathbf{2 , 3}$ and 4, and results are collected in Table $\mathbf{1}$.

\subsection{Photo-dimerization properties}

Coumarin-modified EVOH copolymers were irradiated with a UV lamp to study the photo-dimerization reaction of coumarin in the different systems. The photodimerization process was estimated with UV-vis spectrophotometry by following the decreasing of the absorption band of coumarin double bond at $320 \mathrm{~nm}$ [21]. Likewise, 
the photo-cleavage process of the coumarin dimer triggers the increase of the same band. The photo-conversion degree of coumarin-modified EVOH copolymers is shown in Fig. 5. The higher photo-dimerization yields were obtained for the sample ESH, which is caused by a better mobility of coumarin moieties linked to the succinic chain extender. The results obtained for ENH and EPH are similar, with more rigid spacer groups. The photo-cleavage process is a faster route and is in equilibrium with other parallel reactions, i.e. asymmetric fragmentation [6]. The photo-cleavage process is highly influenced by the mobility and rigidity of coumarin moieties. Also, the photocleavage process in EPH is influenced by the absorption of phthalic ring at around 290 nm (see Fig. S18 in Supporting Information). In this case, phthalic ring can absorb energy at wavelengths close to those of coumarin dimer, avoiding a more efficient photo-cleavage [26].
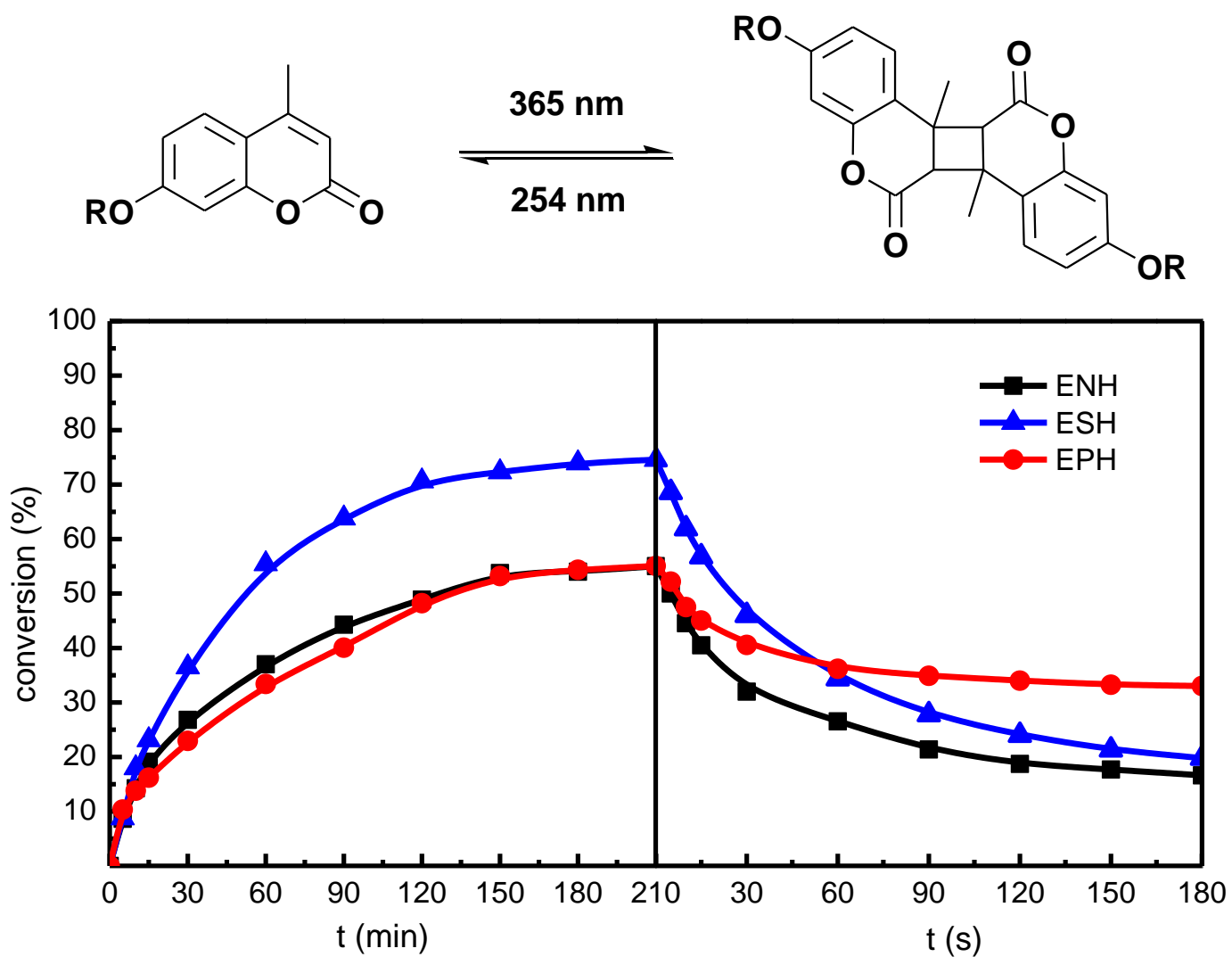

Fig. 5. Photo-dimerization and cleavage process of coumarin and conversion degree of coumarin-modified EVOH copolymers at different times of photo-dimerization (left side) and photo-cleavage (right side) processes.

The SD of coumarin modified copolymers was also calculated by UV spectroscopy in a Nano-drop and the Lambert-Beer's law (Equation 4). The modified 
copolymers were dissolved in DMF and the absorbance of each sample was measured 4 times.

$$
S D_{(U V)}(\%)=\frac{\frac{|A b s|}{\epsilon}}{C_{i}} x 100
$$

Where $|\mathrm{Abs}|$ is the average absorbance and $\mathrm{C}_{\mathrm{i}}$ is the initial concentration of each sample. The absorption coefficient of $\operatorname{HEOMC}\left(\varepsilon_{320}=14226 \pm 211 \mathrm{~mol}^{-1} \mathrm{~L} \mathrm{~cm}^{-1}\right)$, $\operatorname{HEOMCO}\left(\varepsilon_{320}=11184 \pm 517 \mathrm{~mol}^{-1} \mathrm{~L} \mathrm{~cm}^{-1}\right)$ and HEOMC-PH $\left(\varepsilon_{320}=11581 \pm 562 \mathrm{~mol}^{-}\right.$ ${ }^{1} \mathrm{~L} \mathrm{~cm}^{-1}$ ) were previously calculated in DMF. These results are in agreement with the NMR measurements. The compilation of all modified copolymers with molar ratio of each comonomer and the SD of coumarin are shown in Table 1.

It should be observed that SD values obtained by NMR and UV spectroscopy are very similar and, therefore, both techniques could be easily used to study coumarinbased systems.

Table 1. Molar ratio and substitution degree of coumarin in EVOH copolymers

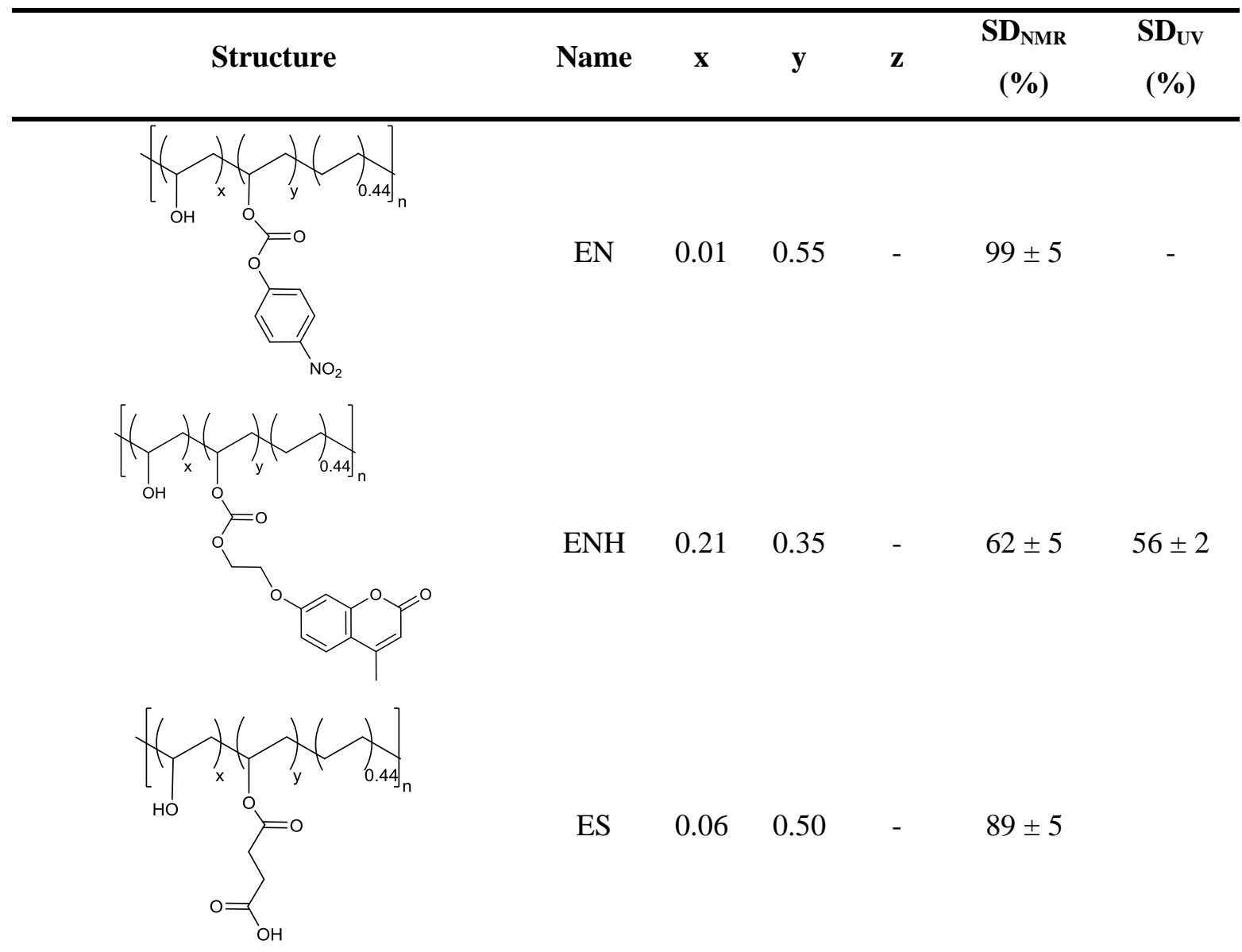




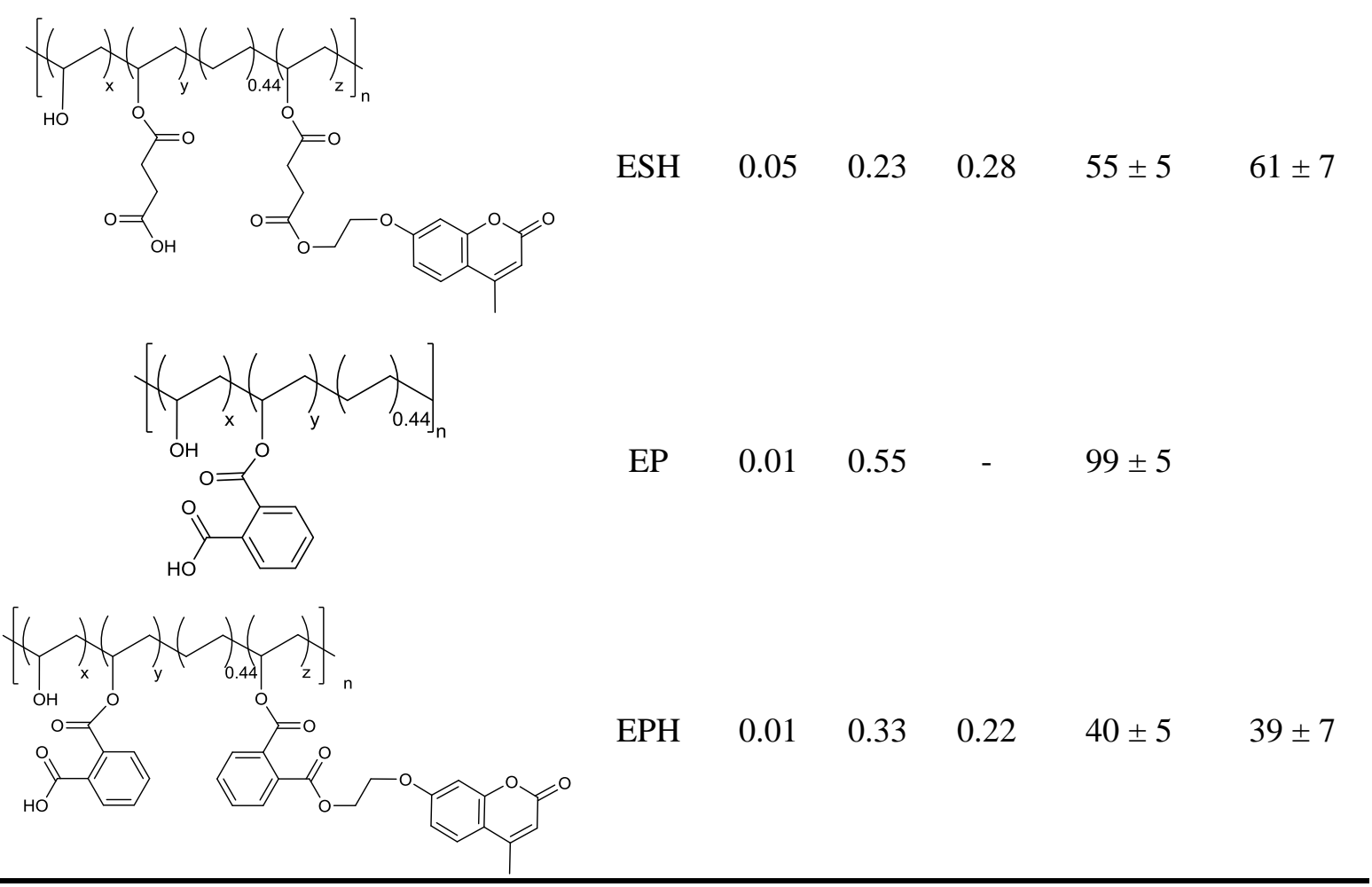

\subsection{Thermal properties}

The thermal properties of modified EVOH copolymers were studied by DSC and TGA and their main results are summarized in Table 2.

Table 2. DSC and TGA thermal properties of coumarin-modified EVOH copolymers.

\begin{tabular}{ccccccc}
\hline Sample & $\mathbf{T}_{\mathbf{g}}\left({ }^{\mathbf{0}} \mathbf{C}\right)$ & $\mathbf{T}_{\mathbf{m}}\left({ }^{\mathbf{0}} \mathbf{C}\right)$ & $\mathbf{T}_{\text {onset }}\left({ }^{\mathbf{0}} \mathbf{C}\right)$ & $\mathbf{T}_{\max }\left({ }^{\mathbf{0}} \mathbf{C}\right)$ & $\mathbf{T}_{\max \text { II }}\left({ }^{\mathbf{0}} \mathbf{C}\right)$ & $\begin{array}{c}\mathbf{T}_{\max \text { III }} \\
\left({ }^{\mathbf{0}} \mathbf{C}\right)\end{array}$ \\
\hline EVOH & 54 & 166 & 329 & 396 & 444 & - \\
$\mathbf{E N}$ & 67 & - & 225 & 271 & 461 & - \\
$\mathbf{E N H}$ & 44 & - & 239 & 303 & 462 & - \\
$\mathbf{E S}$ & 11 & - & 220 & 283 & 322 & 460 \\
$\mathbf{E S H}$ & 42 & - & 216 & 196 & 340 & 457 \\
$\mathbf{E P}$ & 81 & - & 195 & 237 & 295 & 458 \\
$\mathbf{E P H}$ & 72 & - & 195 & 198 & 308 & 462 \\
\hline
\end{tabular}

Standard error: Temperature $\pm 1^{\circ} \mathrm{C}$ 
The EVOH copolymer is composed of ethylene and vinyl alcohol units, with inherent capacity to form three-dimensional networks and with high crystallinity. Its corresponding transitions should appear between these two homopolymers. The DSC heating curve shows two thermal transitions in EVOH (see Fig 6-A); the glass transition of $\mathrm{EVOH}\left(\mathrm{T}_{\mathrm{g}}\right)$ that appears at $54{ }^{\circ} \mathrm{C}$, and the melting of crystalline domains $\left(\mathrm{T}_{\mathrm{m}}\right)$, at 166 ${ }^{\circ} \mathrm{C}$ [27]. The enthalpy of this transition is $79.3 \mathrm{~J} / \mathrm{g}$, that corresponds to $\mathrm{X}_{\mathrm{c}}$ of $50.3 \%$, which is in the range of this copolymer at the performed conditions. Nevertheless, a total loss of crystallinity can be observed when EVOH is modified, provoked by the disruption of the crystalline order produced by the substituents [28]. The different series are also displayed in Fig. 6. When EVOH is activated with $p$-nitrophenyl chloroformate (Fig. 6-B) presents higher stiffness due to the bulky substituent. Therefore, EN shows a higher $\mathrm{T}_{\mathrm{g}}$ than $\mathrm{EVOH}, 67^{\circ} \mathrm{C}$. The incorporation of HEOMC leads to the elimination of nitrophenyl group and increase the flexibility; then, $\mathrm{ENH}$ displays a $\mathrm{T}_{\mathrm{g}}$ at $44^{\circ} \mathrm{C}$. The introduction of coumarin leads to intramolecular interactions between themselves or with the free hydroxyl groups in EVOH [22]. In contrast, the chemical modification of EVOH with succinic anhydride (Fig. 6-C) provokes a diminishment on the $T_{g}$ from 54 ${ }^{\circ} \mathrm{C}$ to $11^{\circ} \mathrm{C}$. Succinic moieties provide higher mobility to the polymer matrix leading to a reduction of the $\mathrm{T}_{\mathrm{g}}$ value and as happen with $\mathrm{EN}$, its insertion inhibit the crystallization of EVOH [29]. The posterior incorporation of HEOMC to obtain ESH, gives as result a movement restriction due to coumarin moieties and then, the $\mathrm{T}_{\mathrm{g}}$ rises up to $42{ }^{\circ} \mathrm{C}$. Meanwhile, the modification with phthalic anhydride introduces more rigidity to $\mathrm{EVOH}$, resulting in the highest value of $\mathrm{T}_{\mathrm{g}}\left(81^{\circ} \mathrm{C}\right)$ (Fig. 6-D). Again, when HEOMC is incorporated to obtain $\mathrm{EPH}$, this gives a slight flexibility even though its $\mathrm{T}_{\mathrm{g}}$ is still high, $72{ }^{\circ} \mathrm{C}$ in part due to its smaller modification degree. 

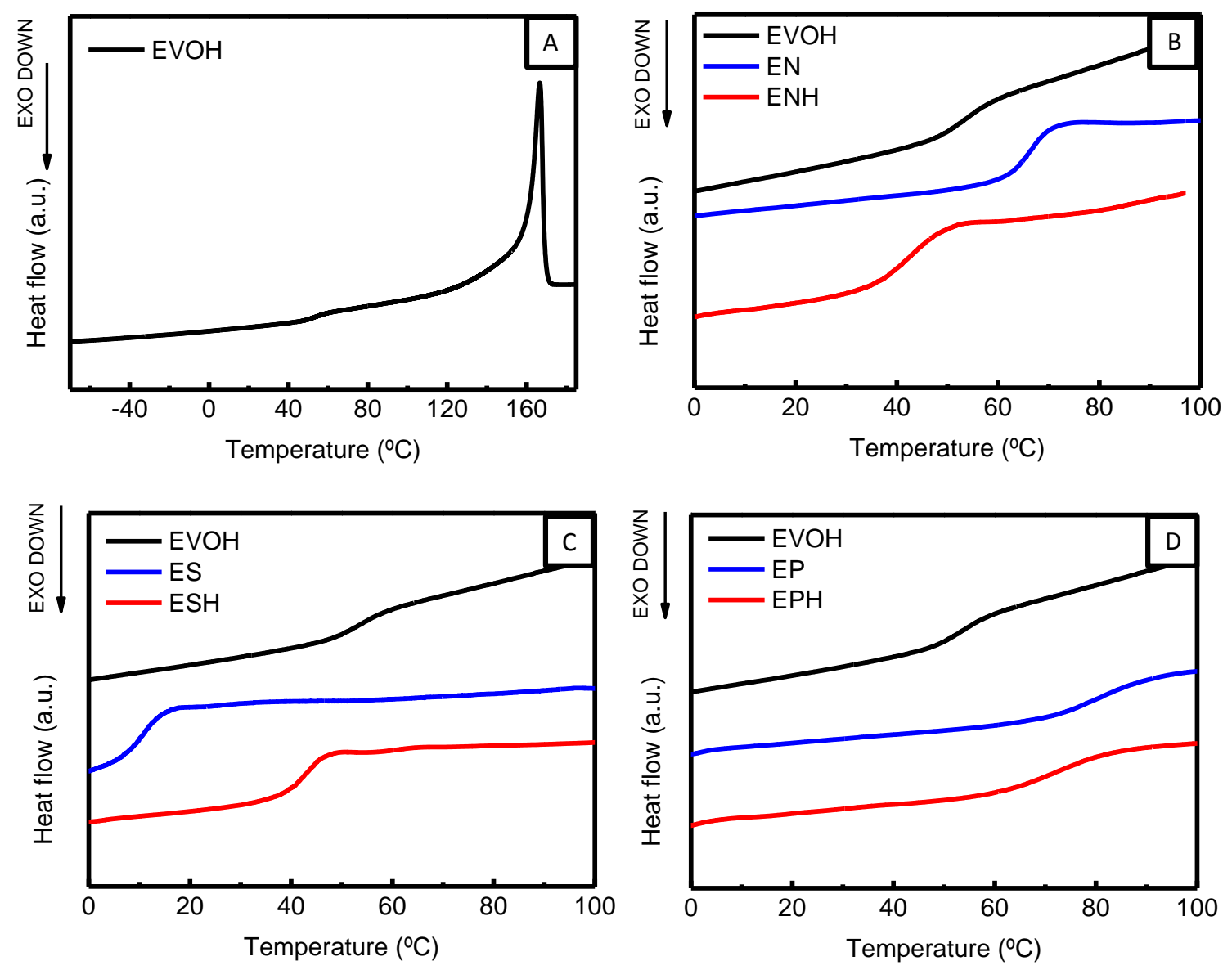

Fig. 6. DSC thermograms of all series of coumarin-modified EVOH copolymers. EVOH (A), ENH family (B); ESH family (C) and EPH family (D).

In order to analyze the thermal stability of EVOH copolymers, TGA measurements were performed. Weight loss and DTG results are shown in Fig. 7. It is well-known that polyethylene acts as a thermal stabilizer in EVOH copolymers, therefore two peaks of maximum degradation temperature are shown in the DTG curves. The first one appears at $396{ }^{\circ} \mathrm{C}$, corresponding to vinyl alcohol units, which matches with the PVA degradation [30]. The second peak at $444^{\circ} \mathrm{C}$ corresponds to the ethylene degradation [31]. In general, the degradation starts at lower temperatures in modified EVOH copolymers. Nevertheless, the modification of the EVOH copolymer with coumarin induces higher maximum degradation temperatures corresponding to the ethylene degradation. This behavior could be ascribed to the antioxidant ability of coumarin [32], as it was already observed in other polymeric matrix such as poly( $\varepsilon$ caprolactone) (PCL) [7]. This effect is especially marked in the sample ENH, which presents the higher value of $\mathrm{T}_{\max }\left(462{ }^{\circ} \mathrm{C}\right)$ due to the higher amount of coumarin in this formulation (see Table 1 with the highest degree of substitution). It should be noted that the samples ESH and EPH show three degradation steps in the thermogram. The lower 
substitution degree in these copolymers when coumarin is incorporated leads to different interactions between structure of activator, unreacted hydroxyl groups and coumarin moieties.
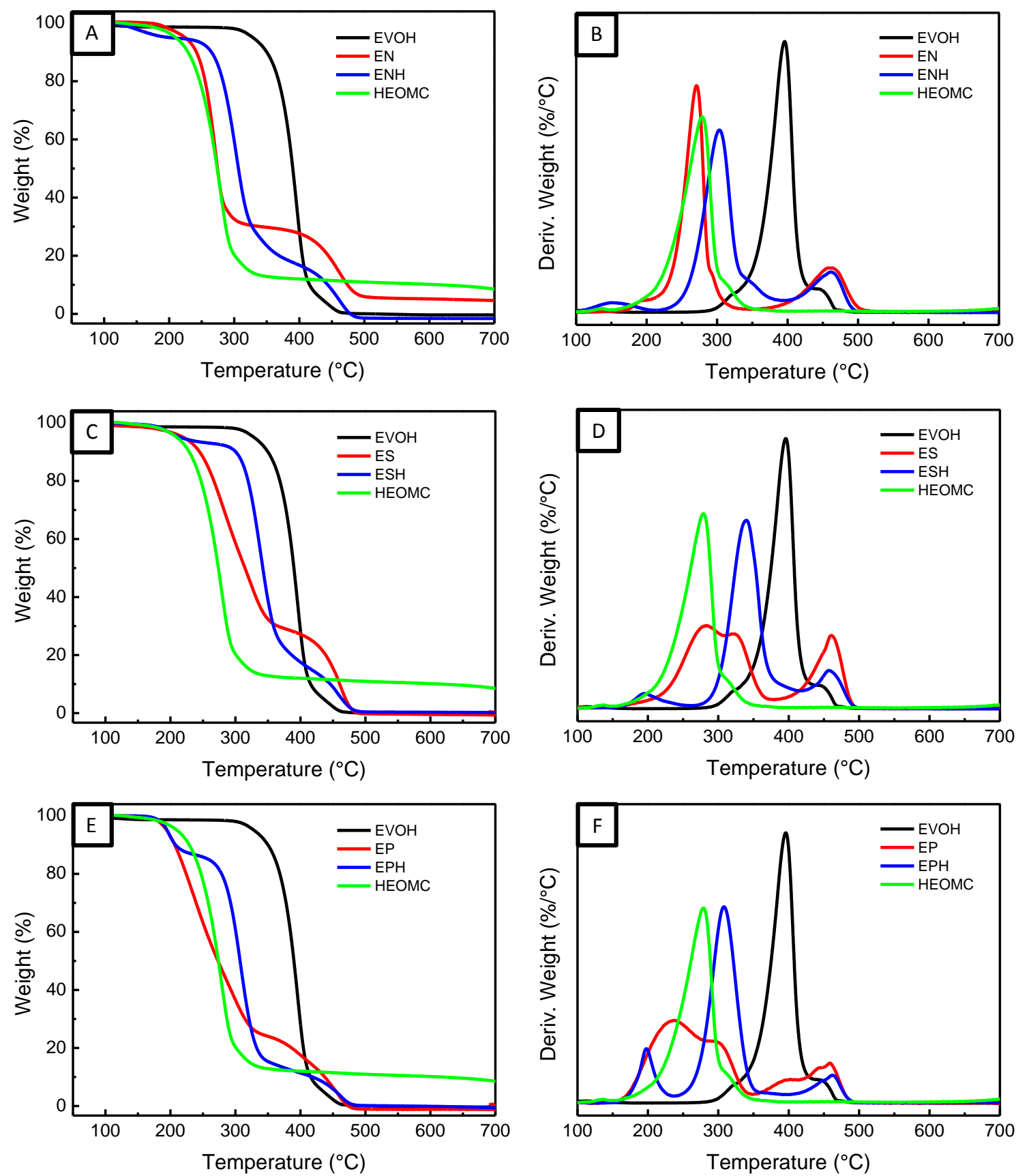

Fig. 7. Thermogravimetric analysis of all series: TGA (A) and DTG (B) of ENH family; ESH family (B, C) and EPH family (E, F). 


\subsection{Microhardness}

The mechanical properties of coumarin-modified EVOH copolymers were studied by microhardness test to evaluate the elastic recovery or the resistance to deformation before and after photo-dimerization process. The polymer modification usually leads to an arrangement between the moieties, which can interact with themselves or show entanglements. This behavior produces a variation in the permanent plastic deformation at the surface of the polymeric film.

The MH results are shown in Table 3. In general, the increase in the MH is related with the entanglement of the modified chains, as well as the interactions between coumarin moieties. In the case of $\mathrm{EVOH}$, the irradiation could produce a film annealing with an increase of crystallinity and higher rigidity. This fact is not possible in modified copolymers due to the absence of crystallinity. For that reason, it is expected that neat EVOH presents lower values of $\mathrm{MH}$ than modified copolymers. Additionally, ENH shows high MH values, which is similar to that of ESH and higher than that of EPH. These values are in concordance with the already commented restriction on the mobility of polymer chains, i.e. $\mathrm{T}_{\mathrm{g}}$ (see Table 2 ) and the degree of coumarin incorporation. There are not significant variations in the $\mathrm{MH}$ with the irradiation process with the exception of the sample ESH, which shows the highest photo-crosslinking degree (75\%) of coumarin. This behavior can be ascribed to the higher flexibility of succinic extender that favors the photo-dimerization process.

Table 3. Surface properties of coumarin-modified EVOH copolymers. The irradiated materials are depicted with "i-" before the name of the sample.

\begin{tabular}{cccc}
\hline Sample & MH (MPa) & WCA $\left(^{\mathbf{o}}\right)$ & $\mathbf{m}_{\text {ads }}\left(\mathbf{n g} / \mathbf{c m}^{2}\right)$ \\
\hline EVOH & $166 \pm 10$ & $87 \pm 5$ & $75 \pm 1$ \\
i-EVOH & $188 \pm 14$ & $86 \pm 4$ & $75 \pm 2$ \\
ENH & $276 \pm 2$ & $78 \pm 2$ & $19 \pm 1$ \\
i-ENH & $266 \pm 5$ & $85 \pm 1$ & n.d. \\
ESH & $260 \pm 5$ & $76 \pm 1$ & $8 \pm 0$ \\
i-ESH & $232 \pm 1$ & $80 \pm 2$ & n.d. \\
EPH & $239 \pm 2$ & $76 \pm 5$ & $18 \pm 0$ \\
\hline
\end{tabular}




\begin{tabular}{cccc}
\hline i-EPH & $235 \pm 14$ & $83 \pm 2$ & $48 \pm 4$ \\
\hline
\end{tabular}

n.d. non detected adsorption

\subsection{Surface wettability}

The surface wettability of the coumarin-modified EVOH copolymers before and after UV irradiation process was studied by water contact angle. The results are also collected in Table 3 and can be considered as hydrophilic surfaces with contact angles lower than $90^{\circ}$. As expected, the irradiation of neat EVOH does not modify the surface, since it does not contain coumarin groups; however, a film annealing can be performed with an increase of crystallinity and higher rigidity, which is not significant to modify its water contact angle. The value of neat $\mathrm{EVOH}$ was in the range of already reported works of EVOH with $44 \%$ of ethylene content [33]. Generally, the hydrophilic behavior of $\mathrm{EVOH}$ is slightly increased when $\mathrm{EVOH}$ is modified with coumarin derivatives because the modification intercepts the inter- and intramolecular bonds between hydroxyl groups present in the vinyl alcohol fraction of EVOH [33], leaving free hydroxyl groups able to interact with water at the surface of the film and, thus, enhancing the surface wettability of the materials. This is the case of ENH with the higher modification degree with coumarin and free vinyl alcohol units. In the case of ESH and EPH, with lower modification degrees, the rest of vinyl alcohol units are capped with succinic and phthalic acid moieties, respectively. These groups could interact between themselves or be exposed at the surface, enhancing their wettability. The differences between ENH, ESH and EPH are not significant.

Additionally, SEM images are taken to analyze the surface since it is wellknown that the roughness of surface can influence the contact angle [34, 35]. It is observed in Figure 8 that there are smooth and flat surfaces, therefore, the differences between them have to be due to the chemical structure. 


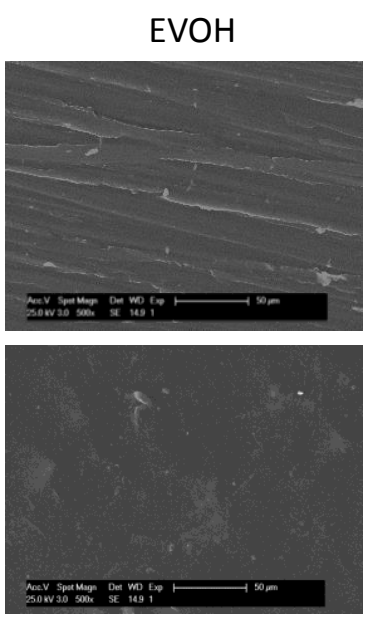

i-EVOH

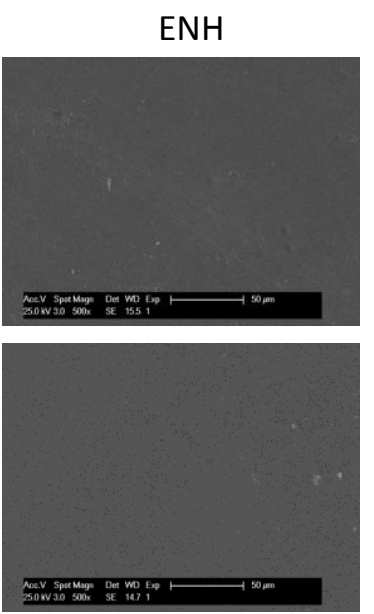

i-ENH
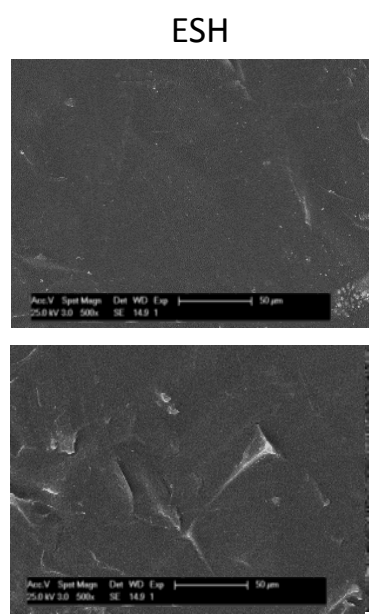

i-ESH
$\mathrm{EPH}$
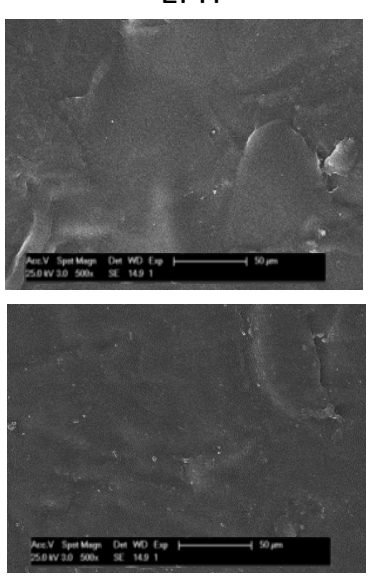

i-EPH

Fig. 8. SEM images of all materials before and after irradiation.

Meanwhile, the photo-crosslinking process in EVOH copolymers bearing a coumarin moiety decreases the distance between hydrophobic groups in coumarin by forming the cyclobutane units [13] and it could induce to a less hydrophilic behavior in the coumarin-modified copolymers.

\subsection{Antifouling properties}

The protein absorption experiment was performed to study the antifouling properties of the resulting coumarin-modified EVOH copolymers before and after UV irradiation process. The samples with approximately $1 \mathrm{~cm}^{2}$ of surface area were incubated into the bovine serum albumin solution. The results of BSA-FITC adsorbed mass per unit area, $\mathrm{m}_{\mathrm{ads}}$, are shown in the Table 3. The absorption of BSA onto the surface of the film is related with their hydrophobic performance [36]. Generally, the absorption of BSA onto the surface of the copolymers is reduced when EVOH is modified with coumarin [18]. In effect, from the data collected in Table 3, it is clearly observed that the modification with coumarin enhances the protein-adsorptionresistance properties in EVOH modified copolymers. The amount of BSA adsorbed on the surfaces is much smaller in coumarin derivatives films that the protein adsorbed on EVOH. Moreover, the photo-crosslinking of coumarin seems to reduce even more the adsorption of BSA. This behavior may be due to different factors, including variation of the surface wettability due to the changes in the chemical structure after photodimerization. 


\section{Conclusions}

Coumarin moieties as photo-responsive segments have been successfully grafted to EVOH copolymers by activation with different chain extenders. Copolymers were characterized by FTIR, ${ }^{1} \mathrm{H}$ and ${ }^{13} \mathrm{C}$ NMR. The materials exhibited reversible photodimerization and photo-cleavage processes, whose conversion degree was conditioned by the nature of the chain extender. Thermal properties reveal that the modification induces to a complete loss of crystallinity and a significant alteration of the glass transition temperature. Likewise, coumarin triggered a higher thermal stability corresponding to the ethylene degradation of the final material. The photo-crosslinking produces a slightly increase of the hydrophilic behavior and also to render materials with enhanced antifouling properties. Therefore, the coumarin moieties grafted onto EVOH copolymers allowed to obtain interesting materials that could be capable to act as photo-responsive polymeric coatings with tunable hydrophilicity and antifouling performance by varying the chain extender used. These results suggest that both ENH and ESH copolymers achieved the greatest photo-responsive, thermal, mechanical and antifouling properties.

\section{Acknowledgements}

Authors thank Spanish Ministry of Science and Innovation (Projects MAT2016-78437R MAT2017-88123-P), the Agencia Estatal de Investigación (AEI, Spain) and Fondo Europeo de Desarrollo Regional (FEDER, EU). M.P.A. and L.P. acknowledge the Juan de la Cierva (FJCI-2014-20630) and Ramon y Cajal (RYC-2014-15595) contracts from the MINECO, respectively. A.C. also acknowledges his FPU fellowship FPU18/01776.

\section{Data availability}

The data that support the findings of this study are openly available in Digital.CSIC at https://digital.csic.es/.

\section{References}

[1] J. Lagaron, R. Catalá, R. Gavara, Structural characteristics defining high barrier properties in polymeric materials, Mater. Sci. Technol. 20(1) (2004) 1-7. https://doi.org/10.1179/026708304225010442 
[2] T. Sadik, V. Massardier, F. Becquart, M. Taha, Synthesis and characterizations of poly(ethylene-co-vinylalcohol)-grafted-poly(3-hydroxybutyrate-co-hydroxyvalerate) copolymers, Polymer 53(21) (2012) 4585-4594. 10.1016/j.polymer.2012.08.019

[3] V. Muriel-Galet, J.N. Talbert, P. Hernandez-Munoz, R. Gavara, J. Goddard, Covalent immobilization of lysozyme on ethylene vinyl alcohol films for nonmigrating antimicrobial packaging applications, J. Agric. Food Chem. 61(27) (2013) 6720-6727. $10.1021 / \mathrm{jf} 401818 \mathrm{u}$

[4] C. Maes, W. Luyten, G. Herremans, R. Peeters, R. Carleer, M. Buntinx, Recent Updates on the Barrier Properties of Ethylene Vinyl Alcohol Copolymer (EVOH): A Review, Polym. Rev. (2017) 1-38. 10.1080/15583724.2017.1394323

[5] S.I. Hong, K.B. Kim, Y. Lee, S.Y. Cho, J.A. Ko, S.K. Hong, H.J. Park, Surface modification of ethylene-vinyl alcohol copolymer treated with plasma source ion implantation, J. Appl. Polym. Sci. 113(5) (2009) 2988-2996. 10.1002/app.30383

[6] N. Yonezawa, T. Yoshida, M. Hasegawa, Symmetric and asymmetric photocleavage of the cyclobutane rings in head-to-head coumarin dimers and their lactone-opened derivatives, J. Chem. Soc., Perkin Trans. 1 (0) (1983) 1083-1086. $10.1039 / \mathrm{p} 19830001083$

[7] C. Salgado, M.P. Arrieta, L. Peponi, M. Fernández-García, D. López, Influence of Poly( $\varepsilon$-caprolactone) Molecular Weight and Coumarin Amount on Photo-Responsive Polyurethane Properties, Macromol. Mater. Eng. 302 (2016) 1600515-n/a. 10.1002/mame.201600515

[8] R. Seoane Rivero, P. Bilbao Solaguren, K. Gondra Zubieta, L. Peponi, A. MarcosFernandez, Synthesis, kinetics of photo-dimerization/photo-cleavage and physical properties of coumarin-containing branched polyurethanes based on polycaprolactones, Express Polym. Lett. 10 (2016) 84-95. 10.3144/expresspolymlett.2016.10

[9] L. López-Vilanova, I. Martinez, T. Corrales, F. Catalina, Photoreversible crosslinking of poly-(ethylene-butyl-acrylate) copolymers functionalized with coumarin chromophores using microwave methodology, React. Funct. Polym. 85 (2014) 28-35. https://doi.org/10.1016/j.reactfunctpolym.2014.10.001

[10] R.S. Rivero, P.B. Solaguren, K.G. Zubieta, A. Gonzalez-Jimenez, J. Valentin, A. Marcos-Fernandez, Synthesis and characterization of a photo-crosslinkable polyurethane based on a coumarin-containing polycaprolactone diol, Eur. Polym. J. 76 (2016) 245-255. https://doi.org/10.1016/j.eurpolymj.2016.01.047 
[11] J. He, Y. Zhao, Light-responsive polymer micelles, nano- and microgels based on the reversible photodimerization of coumarin, Dyes Pigm. 89(3) (2011) 278-283. https://doi.org/10.1016/j.dyepig.2010.03.032

[12] M.S. Lee, J.-C. Kim, Photodependent release from poly(vinyl alcohol)/epoxypropoxy coumarin hydrogels, J. Appl. Polym. Sci. 124(5) (2012) 43394345. 10.1002/app.35411

[13] C. Salgado, M.P. Arrieta, L. Peponi, D. López, M. Fernández-García, Photocrosslinkable polyurethanes reinforced with coumarin modified silica nanoparticles for photo-responsive coatings, Prog. Org. Coat. $123 \quad$ (2018) 63-74. https://doi.org/10.1016/j.porgcoat.2018.06.019

[14] C. Salgado, M.P. Arrieta, V. Sessini, L. Peponi, D. López, M. Fernández-García, Functional properties of photo-crosslinkable biodegradable polyurethane nanocomposites, Polym. Degrad. Stab. $178 \quad$ (2020) 109204. https://doi.org/10.1016/j.polymdegradstab.2020.109204

[15] A.A.H. Kadhum, A.A. Al-Amiery, A.Y. Musa, A.B. Mohamad, The antioxidant activity of new coumarin derivatives, Int. J. Mol. Sci. 12(9) (2011) 5747-5761. 10.3390/ijms12095747

[16] C. Salgado, M.P. Arrieta, L. Peponi, M. Fernández-García, D. López, Silicananocomposites of photo-crosslinkable poly (urethane) s based on poly ( $\varepsilon$-caprolactone) and coumarin, Eur. Polym. J. $93 \quad$ (2017) 21-32. https://doi.org/10.1016/j.eurpolymj.2017.05.030

[17] H.J. Patel, M.G. Patel, R.J. Patel, K.H. Patel, R.M. Patel, Synthesis, characterization, thermal studies, and antimicrobial screening of poly (acrylate) $\mathrm{s}$ bearing 4-methyl coumarin side groups, Iran. Polym. J. 17(8) (2008) 635-644.

[18] M. Pérez, M. García, D. Ruiz, J.C. Autino, G. Romanelli, G. Blustein, Antifouling activity of green-synthesized 7-hydroxy-4-methylcoumarin, Mar. Environ. Res. 113 (2016) 134-140. https://doi.org/10.1016/j.marenvres.2015.11.010

[19] C. Kurth, L. Cavas, G. Pohnert, Sulfation mediates activity of zosteric acid against biofilm formation, Biofouling 31(3) (2015) 253-263. 10.1080/08927014.2015.1034697 [20] Z.-C. Wang, D.-Q. Feng, C.-H. Ke, Coumarins from the herb Cnidium monnieri and chemically modified derivatives as antifoulants against Balanus albicostatus and Bugula neritina larvae, Int. J. Mol. Sci. 14(1) (2013) 1197-1206. 10.3390/ijms14011197 
[21] J. Ling, M.Z. Rong, M.Q. Zhang, Coumarin imparts repeated photochemical remendability to polyurethane, J. Mater. Chem. 21(45) (2011) 18373-18380. $10.1039 / \mathrm{c} 1 \mathrm{jm} 13467 \mathrm{a}$

[22] M. Sánchez-Chaves, C. Ruiz, M.L. Cerrada, M. Fernández-García, Novel glycopolymers containing aminosaccharide pendant groups by chemical modification of ethylene-vinyl alcohol copolymers, Polymer 49(12) (2008) 2801-2807. https://doi.org/10.1016/j.polymer.2008.04.047

[23] S. Banerjee, R. Tripathy, D. Cozzens, T. Nagy, S. Keki, M. Zsuga, R. Faust, Photoinduced smart, self-healing polymer sealant for photovoltaics, ACS Appl Mater Interfaces 7(3) (2015) 2064-72. 10.1021/am508096c

[24] M.L. Cerrada, E. Pérez, J.M. Pereña, R. Benavente, Wide-Angle X-ray Diffraction Study of the Phase Behavior of Vinyl Alcohol-Ethylene Copolymers, Macromolecules 31(8) (1998) 2559-2564. 10.1021/ma9705127

[25] T. Moritani, I. Kuruma, K. Shibatani, Y. Fujiwara, Tacticity of poly (vinyl alcohol) studied by nuclear magnetic resonance of hydroxyl protons, Macromolecules 5(5) (1972) 577-580. https://doi.org/10.1021/ma60029a010

[26] A.I. Scott, Interpretation of the Ultraviolet Spectra of Natural Products: International Series of Monographs on Organic Chemistry, Elsevier2013. 1483137201

[27] C. Bunn, H. Peiser, Mixed crystal formation in high polymers, Nature 159(4031) (1947) 161-162. 10.1038/159161b0

[28] M. Sánchez- Chaves, M. Fernández- García, M. Cerrada, Ethylene- vinyl alcohol copolymers partially modified with benzoate groups: Study of their polymorphic behavior, J. Polym. Sci., Part B: Polym. Phys. 45(9) (2007) 1026-1036. https://doi.org/10.1002/polb.21073

[29] S. De Petris, P. Laurienzo, M. Malinconico, M. Pracella, M. Zendron, Study of blends of nylon 6 with EVOH and carboxyl- modified EVOH and a preliminary approach to films for packaging applications, J. Appl. Polym. Sci. 68(4) (1998) 637648. https://doi.org/10.1002/(SICI)1097-4628(19980425)68:4<637::AIDAPP15>3.0.CO;2-O

[30] W. Jiang, X. Qiao, K. Sun, Mechanical and thermal properties of thermoplastic acetylated starch/poly(ethylene-co-vinyl alcohol) blends, Carbohydr. Polym. 65(2) (2006) 139-143. https://doi.org/10.1016/j.carbpol.2005.12.038 
[31] V.A. Alvarez, R.A. Ruseckaite, A. Vázquez, Kinetic analysis of thermal degradation in poly(ethylene-vinyl alcohol) copolymers, J. Appl. Polym. Sci. 90(11) (2003) 3157-3163. https://doi.org/10.1002/app.13071

[32] K.C. Fylaktakidou, D.J. Hadjipavlou-Litina, K.E. Litinas, D.N. Nicolaides, Natural and synthetic coumarin derivatives with anti-inflammatory/antioxidant activities, Curr. Pharm. Des. 10(30) (2004) 3813-3833. 10.2174/1381612043382710

[33] J. Zhou, S. Meng, Z. Guo, Q. Du, W. Zhong, Phosphorylcholine-modified poly(ethylene-co-vinyl alcohol) microporous membranes with improved proteinadsorption-resistance property, J. Membr. Sci. 305(1) (2007) 279-286. https://doi.org/10.1016/j.memsci.2007.08.013

[34] R.N. Wenzel, Surface Roughness and Contact Angle, The Journal of Physical and Colloid Chemistry 53(9) (1949) 1466-1467. 10.1021/j150474a015

[35] Q. Zhang, H. Liu, X. Zhan, F. Chen, J. Yan, H. Tang, Microstructure and antibacterial performance of functionalized polyurethane based on polysiloxane tethered cationic biocides, RSC Advances 5(95) (2015) 77508-77517. 10.1039/C5RA12945A [36] R. Lv, J. Zhou, Q. Du, H. Wang, W. Zhong, Preparation and characterization of EVOH/PVP membranes via thermally induced phase separation, J. Membr. Sci. 281(12) (2006) 700-706. https://doi.org/10.1016/j.memsci.2006.04.042 